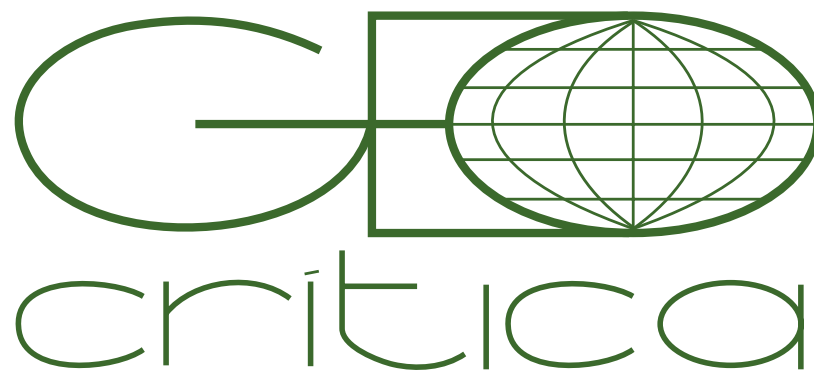

Scripta Nova

Revista Electrónica de Geografía y Ciencias Sociales Universidad de Barcelona

1 de mayo de 2017

\title{
APORÍAS DE UNA IDEOLOGÍA URBANÍSTICA: ARQUITECTURA, TERRITORIO Y CAPITALISMO EN EL TRABAJO DE MARTIN WAGNER
}

\author{
Álvaro Sevilla-Buitrago \\ Recibido: 31 de mayo de 2016; Aceptado sin correcciones: 10 de julio de 2016
}

\begin{abstract}
Aporías de una ideología urbanística: arquitectura, territorio y capitalismo en el trabajo de Martin Wagner (Resumen)
\end{abstract}

La arquitectura y el urbanismo del Movimiento Moderno se presentaron inicialmente como artífices de una transformación socioespacial emancipadora, pero parte de su legado resultó tremendamente lesivo para las ciudades y sus habitantes más humildes. Este artículo explora esa paradoja mediante un análisis del trabajo de Martin Wagner - figura tradicionalmente destacada por su compromiso político- con especial atención a una etapa apenas conocida de su carrera: su actividad docente e investigadora en la Universidad de Harvard. Wagner desarrolló en EE.UU. intuiciones previas sobre una 'rehabilitación' general del modelo urbano y regional, siguiendo un principio intelectual explícito de asimilar en el proceso de diseño la lógica del capital y el desarrollo espacial desigual con el fin de asegurar la viabilidad de sus propuestas. Aunque su autor las presentó como un nuevo patrón de asentamiento ideado "para el pueblo y por el pueblo", esta visión prefigura algunos de los episodios más sombríos del urbanismo de las décadas posteriores. En

La investigación para este artículo fue apoyada por una beca de la Comisión Fulbright y una ayuda José Castillejo del Ministerio de Educación, Cultura y Deporte de España. Inés Zalduendo, directora de la Frances Loeb Library de Harvard Graduate School of Design, y el personal de la misma facilitaron enormemente el trabajo de archivo. su particular crudeza el Wagner americano permite comprender mejor no sólo su contribución durante la República de Weimar, sino también el alcance del 'déficit' político, contradicciones y aporías de un sector dominante de la ideología arquitectónica y urbanística en el siglo XX.

Palabras clave: Martin Wagner, urbanismo moderno, urbanización capitalista, política del diseño, ideología arquitectónica, Movimiento Moderno.

\section{Aporias of a planning ideology: architecture, territory and capitalism in the work of Martin Wagner (Abstract)}

Modernist architecture and urbanism initially presented themselves as agents of an emancipatory transformation of socio-spatial relations, but part of their legacy was tremendously harmful to cities and their poorest inhabitants. This article explores this paradox analyzing Martin Wagner's work -a figure traditionally noted for its political commitment-in the light of a little-known aspect of his career: his 
teaching and research at Harvard University. In the US Wagner developed previous intuitions about a comprehensive 'rehabilitation' of the urban-regional model, moderating the radicalism of his proposals with an unprecedented intellectual principle: ensuring viability by assimilating the logic of capital and uneven spatial development in the re-imagination of the urbanization process. Wagner presented his vision as a new settlement pattern designed "for the people and by the people", but it actually prefigured some of the darkest episodes of subsequent planning experiences. Thus Wagner's American period helps to consolidate a better understanding not only of his earlier contributions during the Weimar Republic, but also of the political 'deficit' and contradictions of Modernist re-articulations of architectural and planning ideologies.

Keywords: Martin Wagner, Modernist urbanism, capitalist urbanization, politics of design, architectural ideology, Modernism.

No cuesta mucho destruir la memoria de una ciudad. En unos pocos años, entre finales de la década de 1950 y mediados de la siguiente, los habitantes de Boston vieron desaparecer buena parte de los barrios populares aún existentes en el centro urbano, cuyo sustrato se había consolidado durante siglos. Entre el West End y Scollay Square pervivía, hasta ese momento, un mosaico proverbial y recalcitrante de etnias y prácticas sociales profundamente imbricadas en el tejido construido, un denso aglomerado de vivienda de baja calidad y mercados, servicios cotidianos básicos, tabernas, cabarets y otros locales de ocio de animación magnífica y dudosa reputación l. Polacos, italianos, bohemios y marineros convivían en un área que unos sentían como un sustituto del hogar y otros, literalmente, como una ampliación del mismo (figuras 1 y 2)2.

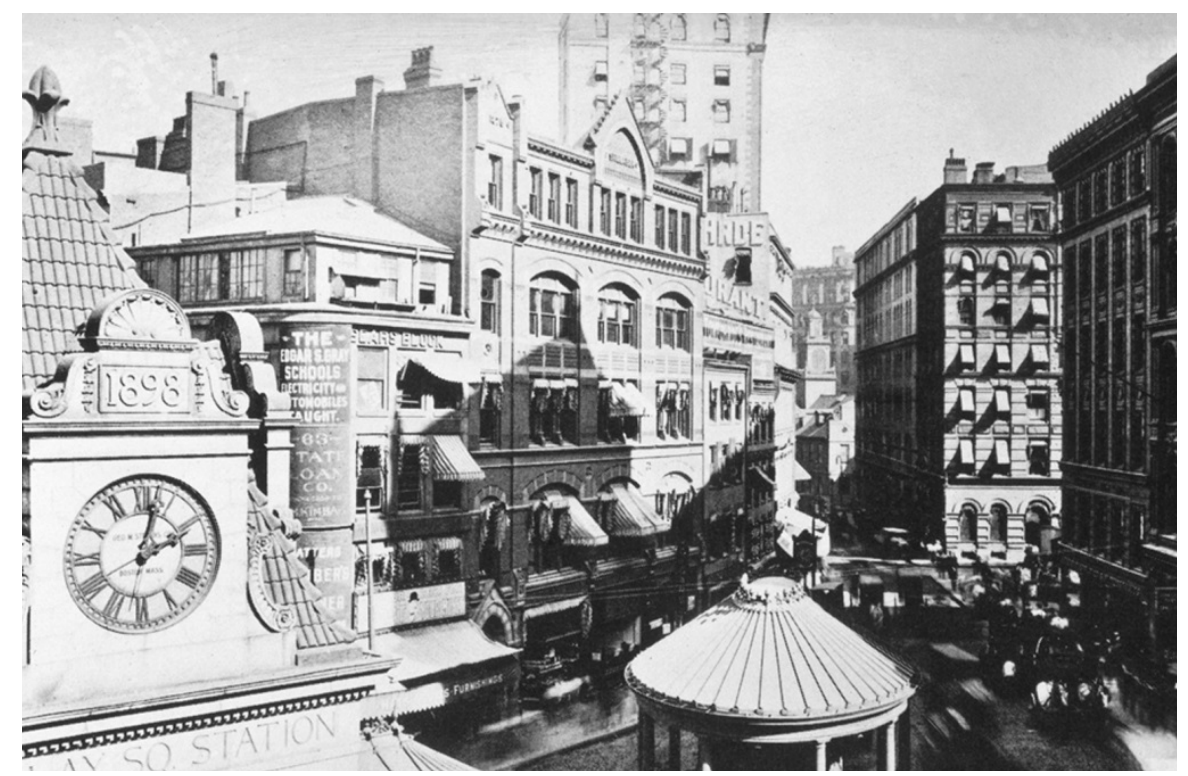

Figura1. Scollay Square, hacia 1910.

Fuente: Frances Loeb Library, Harvard University Graduate School of Design.

1 Sobre la situación de estos ámbitos antes de las operaciones de renovación ver Fisher y Hughes, 1992; Gilbert, 2007; Kruh, 1999.

2 Fried y Gleicher, 1961. 
Pero el Boston popular enmudeció en 1957 con la noticia de la puesta en marcha de la renovación del West End. Los subsiguientes gritos de protesta y lamentos de los cerca de 12.000 residentes desalojados se vieron pronto apagados por el sonido ensordecedor de la maquinaria de demolición (figs. 3,4$)^{3}$. La historia hizo de la "city upon a hill" una pionera en las campañas de urban renewal durante esta época4. Hacia finales de los 60 un abigarrado circuito de calles y más de 800 menudos solares había sido sustituido por tres decenas de predios ocupados por torres de vivienda de lujo y un desierto mineral bautizado como plaza, antesala para los engendros brutalistas construidos, entre otros, por Kallmann McKinnell \& Knowles y Walter Gropius (figuras 5, 6 y 7 ) 5
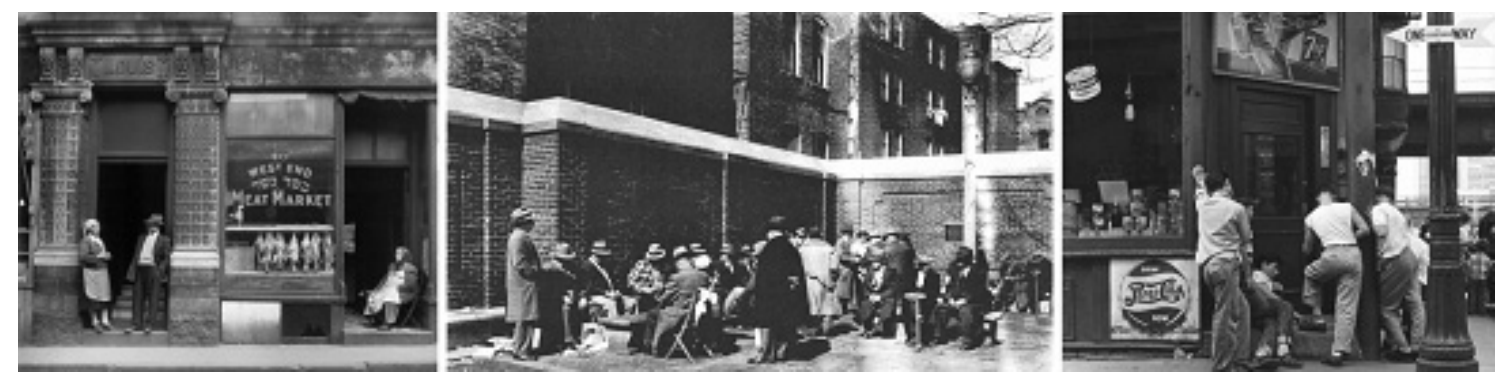

Figura 2. Impresiones de la vida cotidiana en el West End y North End de Boston, entre las décadas de 1940 y 1950.

Fotografías de Jules Aaron. Fuente: Boston Public Library

Apenas un par de meses antes del arranque de la iniciativa en el West End había fallecido un antiguo compañero de Gropius que sin duda hubiera contemplado el espectáculo de la renovación con interés.

Martin Wagner-urbanista, ingeniero-arquitecto, figura fundamental en la política residencial y municipal de la República de Weimar (figura 8)-había pasado las últimas dos décadas de su vida a pocas millas del área de actuación, en Cambridge, ciudad a la que se trasladó para enseñar en la Universidad de Harvard en $1938^{6}$.

Durante ese período defendió la necesidad de una estrategia radical para enfrentarse al problema de la rehabilitación urbana. El eco de sus propuestas resonaría poderosamente en las actuaciones que acabamos de describir. En un momento en que todos concebían la demolición de slums como paso previo para la construcción de vivienda social, Wagner había vislumbrado un nuevo organismo urbano de escala regional, que convertiría el área central en una nueva "corona de la ciudad", reservada para usos conspicuos: grandes centros comerciales, complejos culturales, edificios institucionales y de oficinas y un selecto grupo de viviendas y hoteles de élite.

La prefiguración implícita en este modelo no suponía, en todo caso, una influencia

3 Fisher y Hughes, 1992, p. 12.

4 Mollenkopf, 1983; O'Connor, 1993, p. 124-142; Teaford, 1990.

5 Boston Redevelopment Authority, 1970.

6 Para una visión global de la biografía de Wagner ver Homann, Kieren y Scarpa, 1985; B. Wagner, 1985. 
directa sobre los procesos de renovación urbana en Boston. Y sin embargo los paralelismos eran algo más que una mera coincidencia.

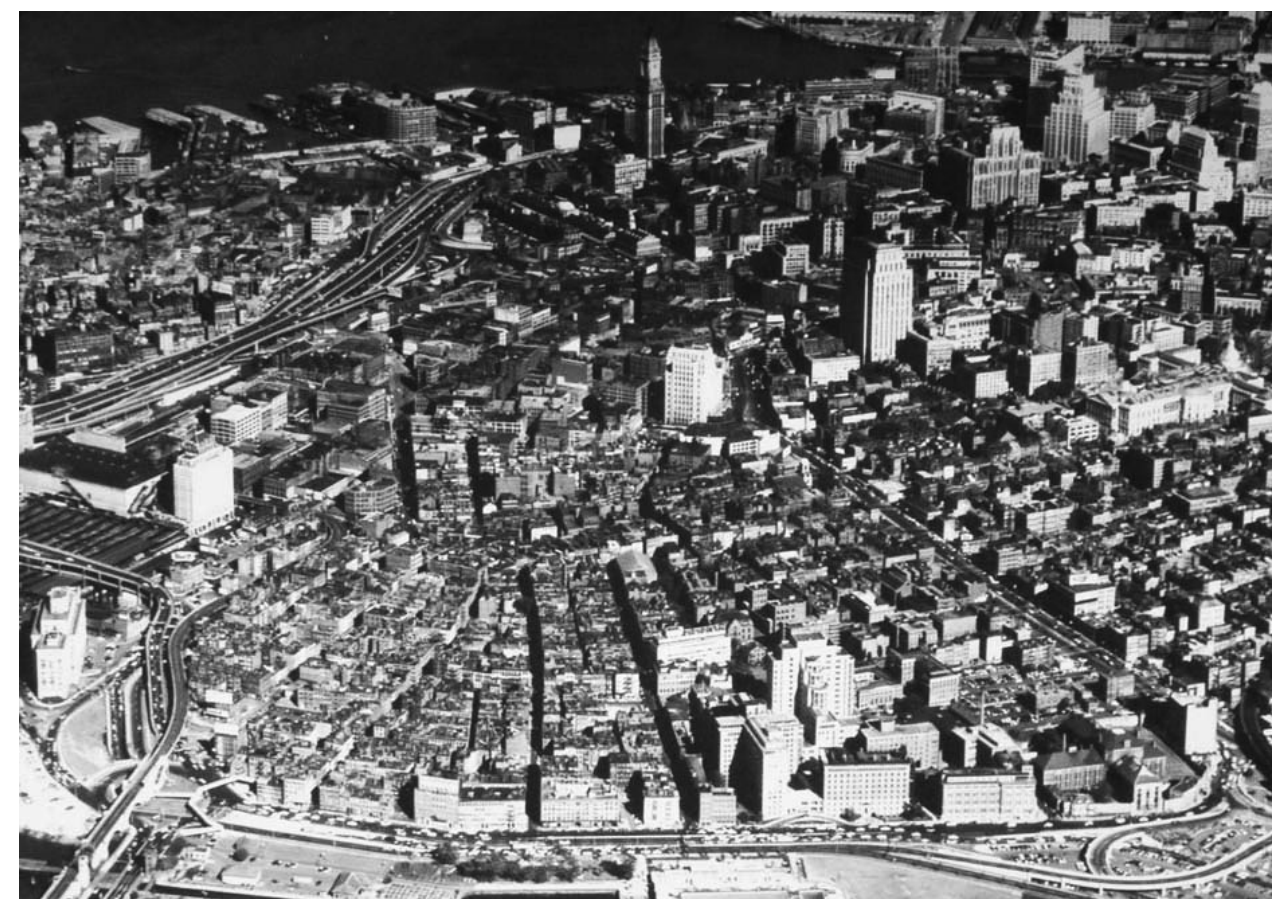

Figura 3. El West End de Boston, a finales de la década de 1950, antes de su demolición. Fuente: West End Museum, Boston.

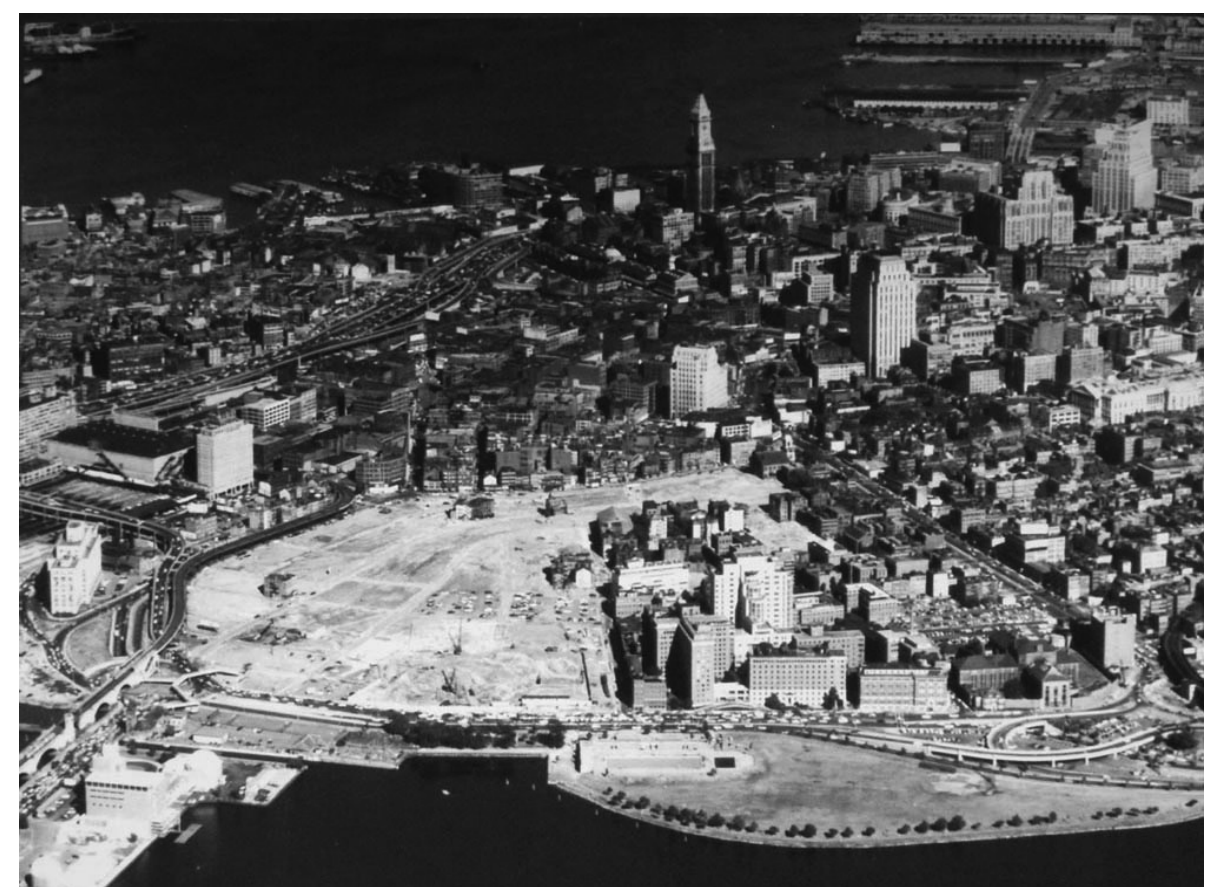

Figura 4. El West End de Boston, a principios de la década de 1960, tras la demolición. Fuente: West End Museum, Boston. 
En su investigación durante estos años Wagner se había impuesto a sí mismo un imperativo teórico poco habitual en su disciplina: pensar la urbanización con el capital, emplear su propia lógica, para hacer viable la magna empresa de rehabilitación metropolitana que tenía entre manos.

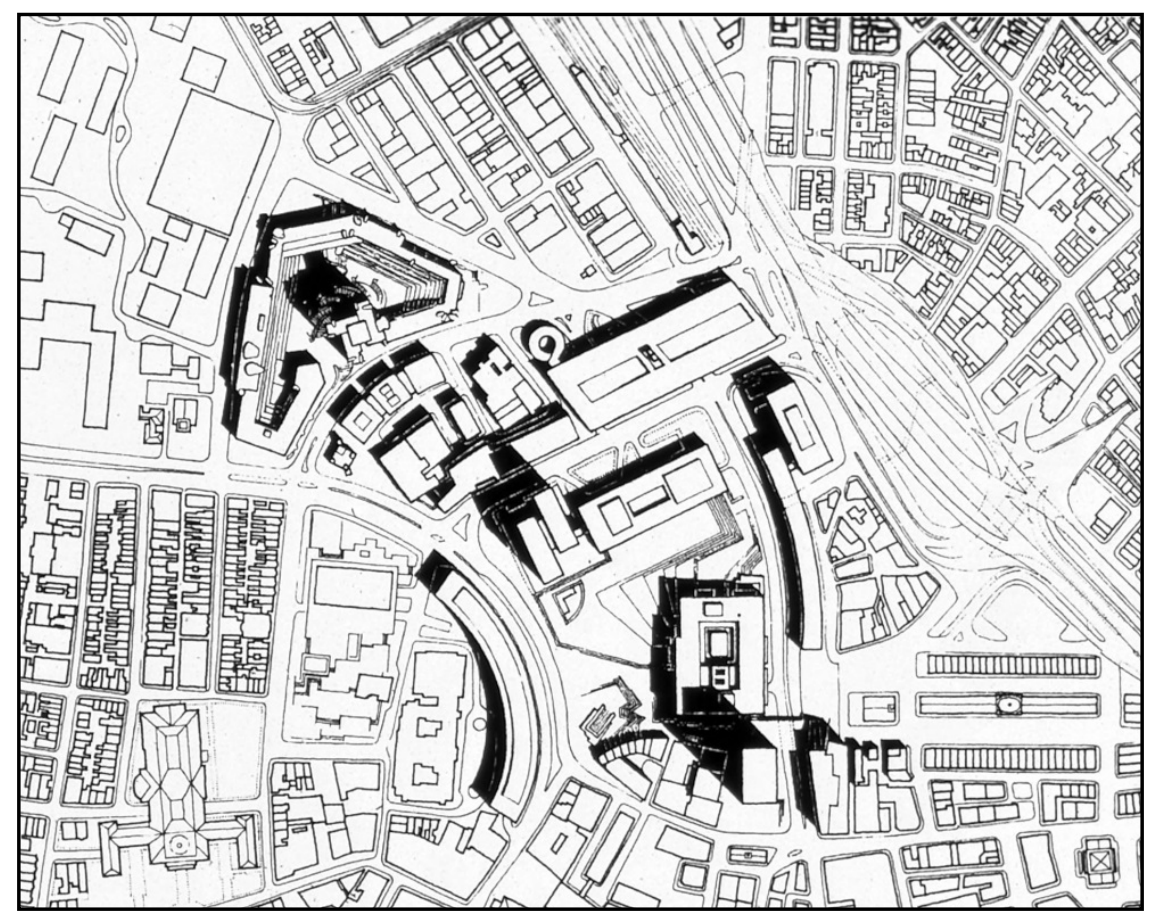

Figura 5. Master Plan de Pei \& Cobb para el Government Center en el área de Scollay Square, versión de 1961.

Fuente: Frances Loeb Library, Harvard University Graduate School of Design.

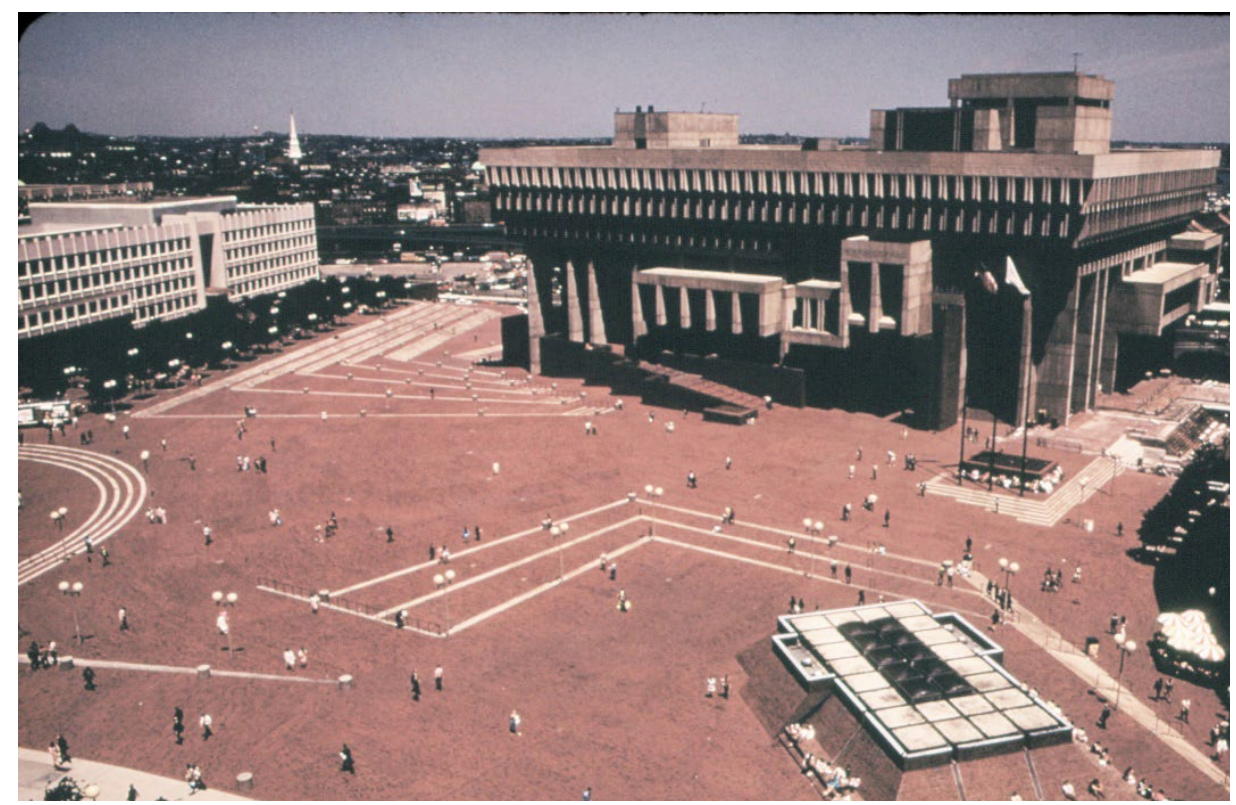

Figura 6. City Hall Square en 1973, con el edificio del ayuntamiento acaparando el protagonismo. Fotografía de Ernst Halberstadt. Fuente: National Archive, College Park, Maryland. 


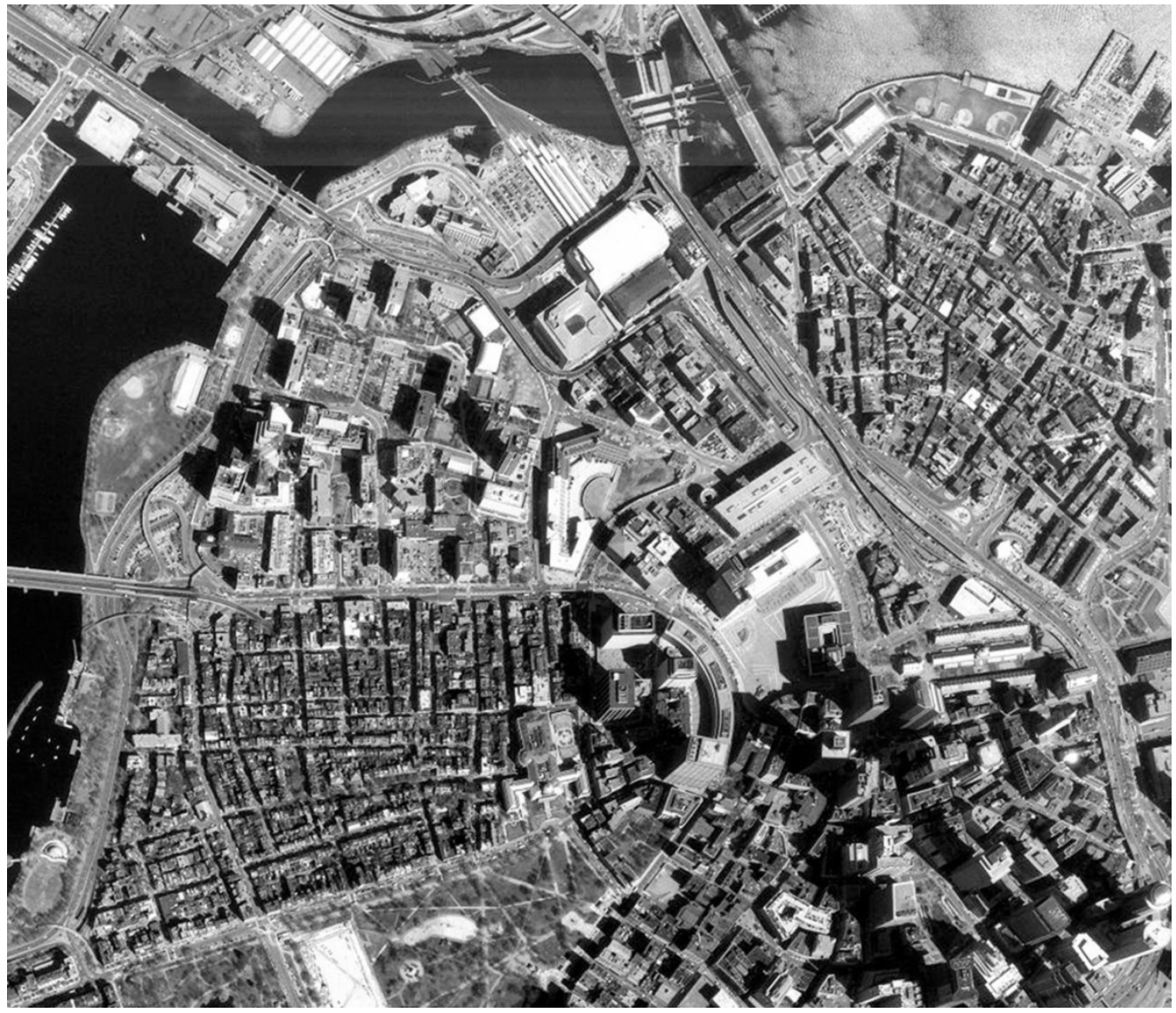

Figura 7. El conjunto del West End y el Government Center, tras la finalización de la renovación urbana, hacia finales de la década de 1960.

Fuente: Frances Loeb Library, Harvard University Graduate School of Design.

De modo análogo, fueron el modelo de gestión y financiación, las limitaciones presupuestarias y las maquinaciones de operadores inmobiliarios las que dieron su impronta particular a la reconstrucción del West End, convirtiéndola en una pionera del urbanismo revanchista en EE.UU. ${ }^{7}$ Nunca antes se había movilizado el aparato estatal en tal escala en un proceso urbanizador que sustituía residencia obrera por espacios para las clases medias-altas. Wagner había denunciado incansablemente la creación de vivienda social en áreas renovadas como un enfoque miope que condenaba a las ciudades a reproducir sus problemas en el tiempo y, más importante, imponía cargas insostenibles sobre la hacienda local. En su lugar, proponía reservar la centralidad de la región a aquellos usos y actividades que pudieran no sólo compensar los elevados costes de una renovación integral y a gran escala, sino incluso generar beneficios, haciendo la iniciativa apetecible para los propietarios de suelo. Los habitantes expulsados de sus residencias en dichas áreas-fundamentalmente clase trabajadora-serían realojados en suburbios de nueva planta.

Resulta fácil, a la luz de estos primeros trazos, identificar al protagonista de este

7 Mollenkopf, 1983, p. 150; O'Connor, 1993, p. 129-134. 
artículo como uno más de la legión de arquitectos y urbanistas que han hecho de su carrera una amplia reverencia a una urbanización capitalista guiada casi exclusivamente por la captación de plusvalías. Al fin y al cabo el propio Wagner afirmaría: "el que juega con el capital debe rendir tributo al capital" ("he who plays with capital must pay tribute to capital" $)^{8}$. Sin embargo estamos hablando de una figura que ha pasado a la historia del urbanismo por su compromiso con los sindicatos alemanes;; del que su propio partido durante la República de Weimar, el Sozialdemokratische Partei Deutschlands (SPD), sospechaba como un infiltrado comunista ${ }^{10}$; uno de los pocos arquitectos de la época que se tomó la molestia de sustentar sus invocaciones a la comunidad con nociones histórico-jurídicas sólidas sobre los comunes anglosajones y germánicos ${ }^{11}$; y por encima de todo, un pensador que presenta enfáticamente la propuesta que acabamos de comentar como un nuevo patrón urbanizador "para el pueblo y por el pueblo" ("for the people and by the people") ${ }^{12}$.

Es intrigante que un personaje con este perfil haya legado contribuciones teóricas en las que se prefiguran buena parte de las grandes transformaciones de las políticas urbanas posteriores, particularmente en su expresión más oscura, de los propios programas de urban renewal en EE.UU. y las políticas de new towns británicas a los procesos de gentrificación y neoliberalización de la urbanización en los países del Norte Global. Este artículo intentará dilucidar dicha paradoja huyendo de una hipótesis simplista que vería a Martin Wagner cayendo del caballo socialista en su camino al Damasco del liberalismo estadounidense. Como indico en el siguiente apartado, nuestro protagonista había abierto ya esa línea de especulación económico-política y espacial en su etapa alemana, tanto en su labor con los sindicatos como en los diversos cargos administrativos que desempeña en diversos ayuntamientos, especialmente como Stadtbaurat en Berlín. Se trata de una etapa bien conocida en algunos círculos de la historiografía arquitectónica y urbanística, que sin embargo han prestado una atención limitada a este factor seminal. Dichas perspectivas, que durante este período se manifiestan sólo in nuce, van a ser desarrolladas hasta sus últimas consecuencias en la etapa americana de Wagner, que sigue siendo prácticamente desconocida, una laguna importante que este artículo contribuye a subsanar con la discusión en el apartado tercero. La investigación para esta sección se ha basado en un estudio exhaustivo del archivo personal de Wagner en la Frances Loeb Library de Graduate School of Design, Harvard University. En su conjunto, este periplo nos mostrará las consecuencias y peligros de una asimilación por el diseño de la lógica del capital en su proyección sobre el proceso urbanizador, así como las contradicciones de dicho planteamiento en el marco del proyecto progresista de parte del Movimiento Moderno. De hecho, tomando el caso de Wagner no quisiera agotar el mensaje de este trabajo en una mera disección historiográfica de su figura,

8 Wagner, 1949a, p. 13.

9 Tafuri, 1984.

10 Scarpa, 1983, p. 54.

11 Ver por ejemplo Wagner, 1951, p. 33-35.

12 Gropius y Wagner, 1942a. 
por necesaria que ésta sea. Por el contrario, mi contribución aspira a emplear este episodio como ejemplo de las repercusiones de lo que podemos denominar el 'déficit político' de la ideología arquitectónica dominante. A este fin dedicaré el último apartado del texto.

\section{Génesis: paradojas políticas y estrategia urbanística en la República de Weimar}

Antes de recalar en la Universidad de Harvard Wagner había viajado a EE.UU. en dos ocasiones. La primera visita se inscribe ya en la paradoja que acabamos de mencionar. En 1924, en un momento álgido de su relación con los sindicatos alemanes, éstos le envían a América como comisario para informar sobre los avances en los sistemas de construcción residencial ${ }^{13}$. Wagner había elogiado en numerosas ocasiones las que considera experiencias fundamentales en el proceso de modernización industrial de este país: las propuestas de Frederick Taylor y Henry Ford. Resulta revelador que nuestro protagonista, ya en ese momento comprometido políticamente con la socialdemocracia y el movimiento obrero organizado, tenga como referentes a dos maestros de la desorganización del control proletario del espacio de trabajo ${ }^{14}$; o que se elija EE.UU. como destino de la investigación, un país inmerso desde 1920 en una dura persecución de la izquierda radical y el sindicalismo autonomista ${ }^{15}$. Como veremos al final de este artículo, esta falta de profundización en el significado social y político de decisiones técnicas, supuestamente racionales, lastrará el potencial emancipador del trabajo de Wagner y de toda una generación de colegas.

Las propuestas con las que regresa a Alemania reforzarán la orientación adoptada unos años antes. Wagner se había acercado a los sindicatos tras el fin de la Primera Guerra Mundial buscando un medio para esquivar la lentitud y rigidez de la burocracia administrativa y los ritmos institucionales. En el empeño por implementar políticas masivas de alojamiento obrero, los sindicatos podían operar con mayor agilidad, como una empresa privada, asegurando la viabilidad de las propuestas sin renunciar a un compromiso con el bienestar de los trabajadores ${ }^{16}$. Se trata de una primera intuición, poblada de contradicciones, sobre las posibilidades de formación de un capital social que simultáneamente queda bajo el control obrero, escapa del circuito de la política institucional y refrenda la lógica del mercado inmobiliario.

Siguiendo esta estrategia los sindicatos y Wagner forjan el Verband sozialer Baubetriebe (VsB), una liga de empresas de construcción social que aspira a agrupar el tejido de cooperativas que habían proliferado durante la época guillermina, fusionándolas y convirtiéndolas en sociedades de responsabilidad limitada ${ }^{17}$.

13 Homann, Kieren y Scarpa, 1985, p. 166, 172.

14 En realidad Wagner no está solo en su interés por ambas figuras, que atraen mucha atención durante esta época en Alemania. La autobiografía de Ford se había traducido al alemán en 1923 y se convirtió rápidamente en un éxito de ventas. Ver Kolinsky y van der Will, 1998, p. 292.

15 Murray, 1980.

16 Scarpa, 1983, p. 19-21.

17 Verband Sozialer Baubetriebe, 1928. 
Se trata por tanto de un proceso de asimilación de tejido económico parcialmente independiente de los mecanismos de mercado en la lógica corporativa. La propuesta recibirá críticas desde ambos extremos del espectro político-tanto el Partido Comunista Alemán (KPD) como los empresarios de la construcción consideran la iniciativa un subterfugio capitalista bajo la máscara de la economía comunitaria ${ }^{18}$ - pero saldrá adelante y ampliará sus perspectivas más tarde. En la primavera de 1924 el ADGB ${ }^{19}$ y el VsB fundan, también siguiendo el consejo de Wagner, la Dewog ${ }^{20}$, y su filial berlinesa, la Gehagg ${ }^{21}$, que se encargará en los años siguientes de promover la famosa campaña de Siedlungen (colonias) en la capital22.

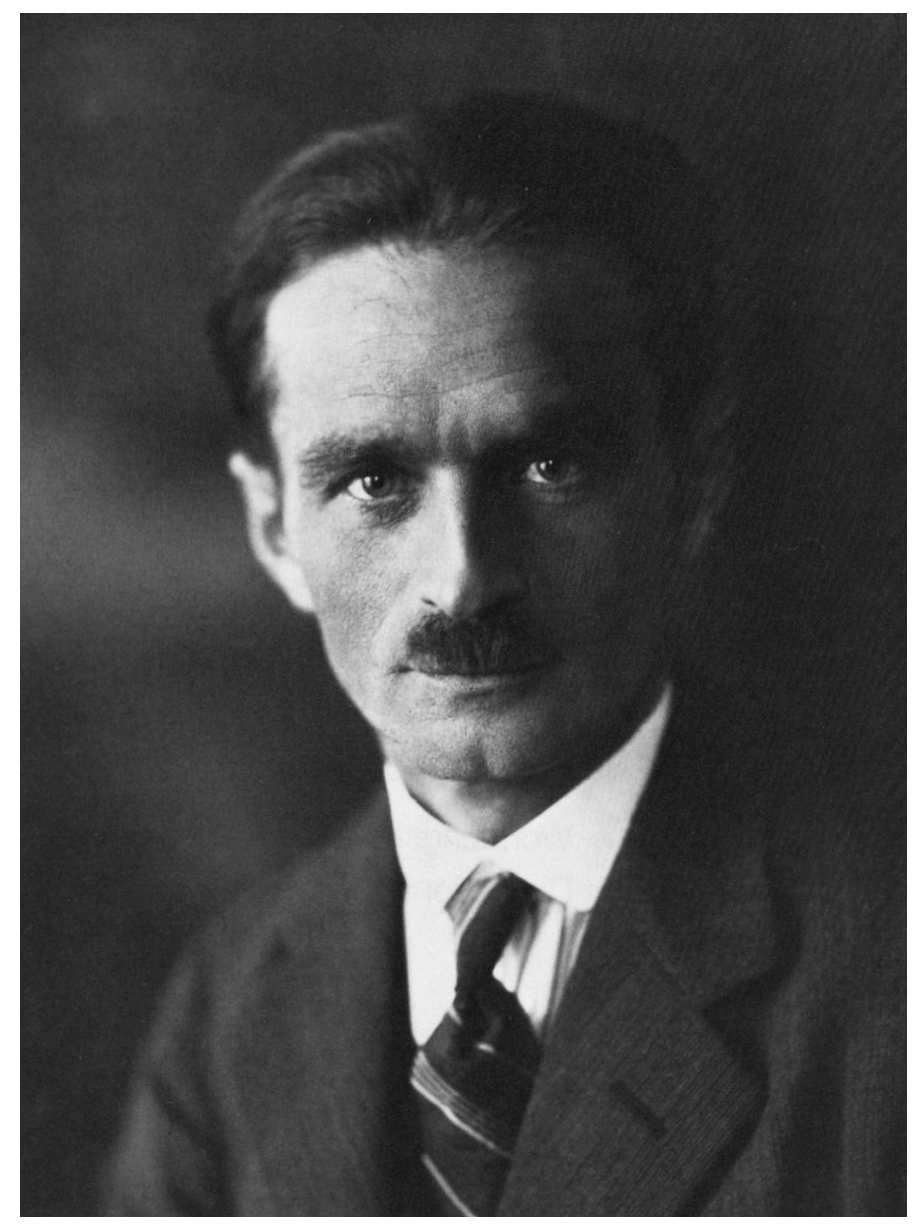

Figura 8. Martin Wagner, hacia 1930.

Fuente: Homann, Kieren y Scarpa, 1985.

18 Scarpa, 1983, p. 26.

19 Allgemeiner Deutscher Gewerkschaftsbund, la principal agrupación sindical durante la República de Weimar.

20 Deutsche Wohnungsfürsorge AG (Compañía Alemana para la Provisión de Vivienda).

21 Gemeinnützige Heimstätten-, Spar- und Bau-Aktiengesellschaft (Compañía de acciones para la Construcción, la Vivienda y el Ahorro).

22 Kaufmann, 1932; Lineke, 1931. 


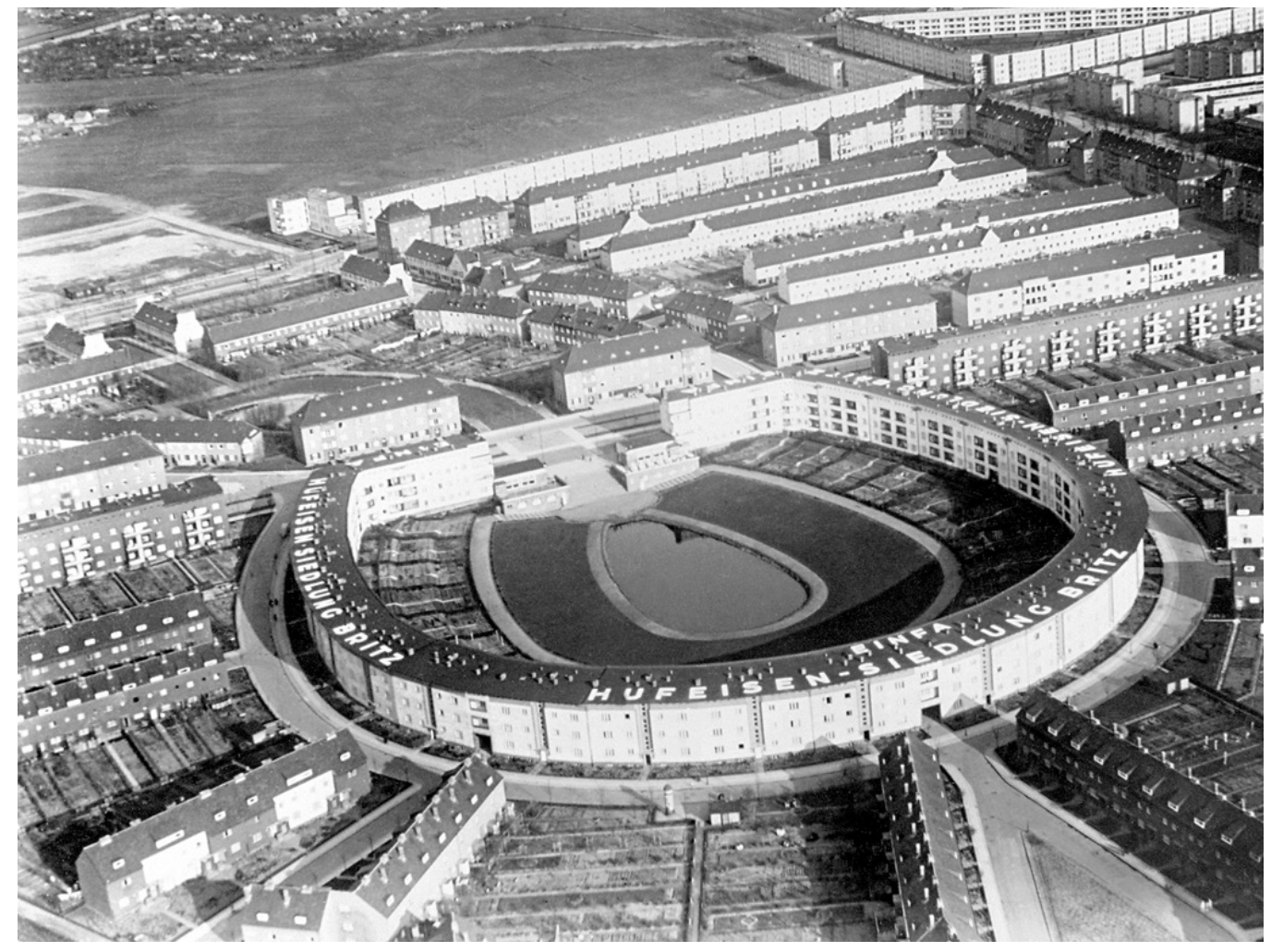

Figura 9. En primer plano, la Hufeisensiedlung de Britz, recién concluida en 1931. Los bloques en segundo término pertenecen a una promoción paralela. Fuente: Archiv für Kunst and Geschichte.

Buena parte de la historiografía de la arquitectura y el urbanismo ha mitificado estas operaciones como expresión conspicua de la progresividad política del Movimiento Moderno en Alemania, una experiencia de vivienda social en la que renombrados arquitectos de vanguardia colaboran con los sindicatos y un ayuntamiento bajo el control de la socialdemocracia ${ }^{23}$. Wagner era, desde luego, la pieza clave en esta encrucijada. Su intervención directa en los proyectos se limitó al diseño de la colonia de Britz junto a Bruno Taut y la supervisión de las líneas generales de estructura urbana del resto de actuaciones, pero su gestión hizo posible la concurrencia de los actores principales, en su triple condición de consejero de los sindicatos, Stadbaurat del ayuntamiento de Berlín-responsable de la Amt für Stadtplanung (Departamento de Planificación Urbana)-y miembro de los círculos de vanguardia arquitectónica del Neues Bauen y Deutscher Werkbund.

A pesar de todo, hay que tomar con cautela el retrato heroico que los historiadores han reconstruido a partir de esta experiencia. Desde el punto de vista de su producción, Wagner-al igual que su coetáneo Ernst May en Frankfurt-animó medidas de reorganización y estandarización de la construcción que perjudicaron

23 AA.VV., 1992; Gravagnuolo, 1998, p. 130-145. 
a un sector de la mano de obra cualificada tradicional ${ }^{24}$. El "sacrificio" no beneficiaba necesariamente a los propios trabajadores. Como Hannes Meyer-arquitecto suizo, segundo director de Bauhaus Dessau, comunista-criticó en 1934, las Siedlungen berlinesas serían habitadas principalmente por clases medias ${ }^{25}$. El propio Wagner reconocerá en una de sus charlas en Harvard que las iniciativas se destinaron a "aquellos estratos de las clases trabajadoras que podían pagar viviendas estandarizadas decentes", resultando imposible realojar a las capas más humildes de la población "en un estilo magnífico"26.

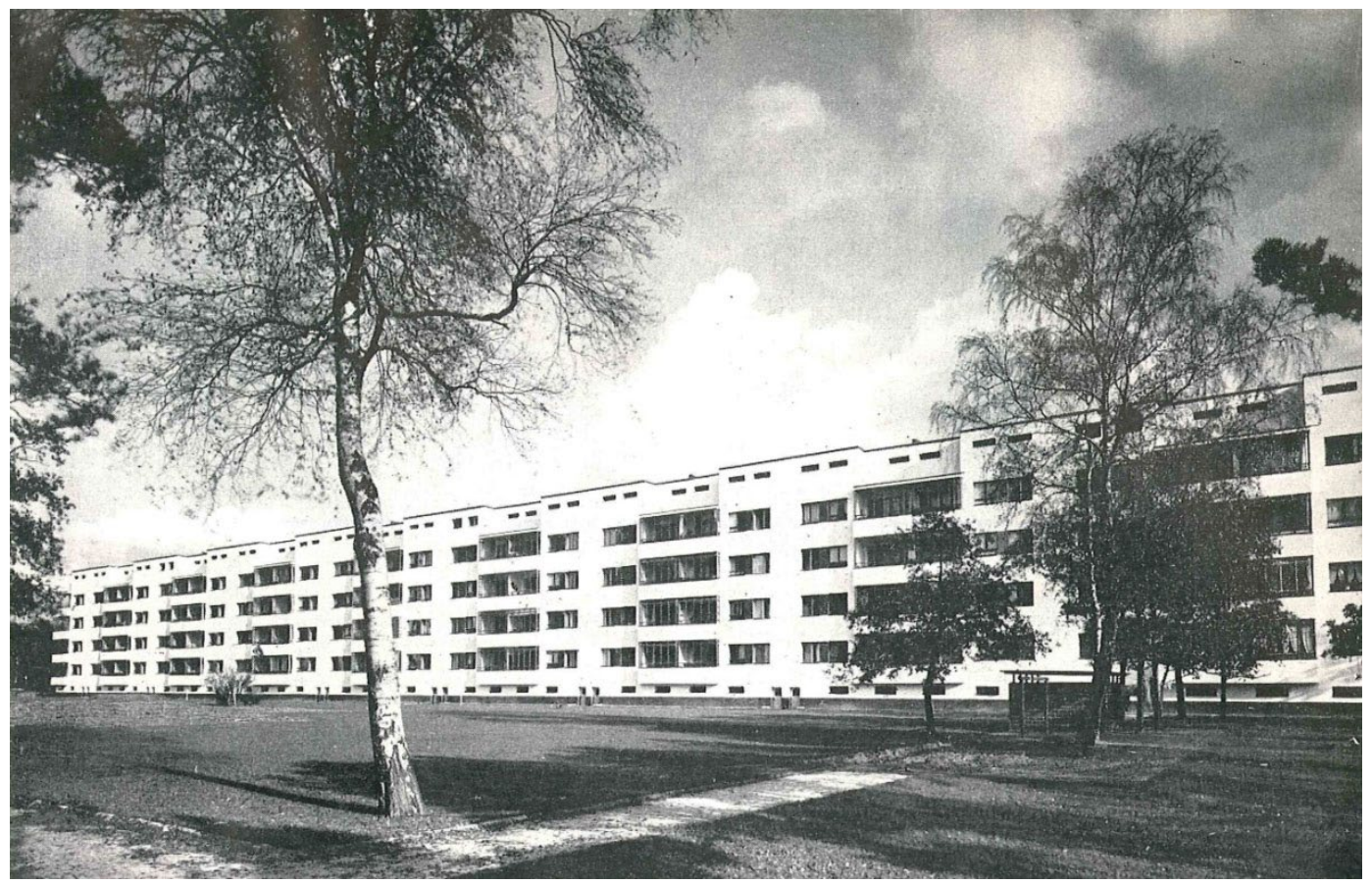

Figura 10. El edificio de Walter Gropius en Siemensstadt,Berlín, a principios de la década de 1930. Fuente: Frances Loeb Library, Harvard University Graduate School of Design.

Un último aspecto, en mi opinión aún más importante, es el propio modelo de ciudad que estas operaciones contribuían a consolidar. En el momento de su creación las colonias eran enclaves suburbanos, alejados de la trama consolidada y a menudo mal conectados a ella, radicalmente opuestos al mundo crepitante y complejo de los barrios populares en el centro de la ciudad, que los trabajadores habían convertido en recurso material y soporte de formas comunitarias de socialización. Las Siedlungen eran espacios inequívocos, de arquitectura limpia y distribución de usos simple y segregada; la vivienda dominaba casi totalmente, acompañada por unos pocos servicios básicos (figuras 9, 10) 27.

24 Meyer, 1972, p. 184-185.

25 Citado en AA.VV., 1992, p. 196.

26 Wagner, s.f. (1), p. 9.

27 Sambricio, 1991. 
Los sindicatos se esforzaban por dotar de vida a los enclaves, organizando actividades colectivas para los nuevos colonos, y los arquitectos intentaban contribuir traduciendo el ideal comunitario a gestos formales, como en el gran abrazo construido del edificio principal en $\mathrm{Britz}^{28}$. Pero dicho empeño era incapaz de reproducir una vitalidad comunitaria que los promotores, por lo demás, deploraban, hecha como estaba del desorden cotidiano de los barrios populares realmente existentes. De hecho podría afirmarse que las Siedlungen intentaban no tanto reproducir como normalizar la comunidad obrera empleando un referente de clase media, continuando el eclipse de la ciudad popular y la emergencia de la nueva urbanidad de los Angestellten por otros medios ${ }^{29}$.

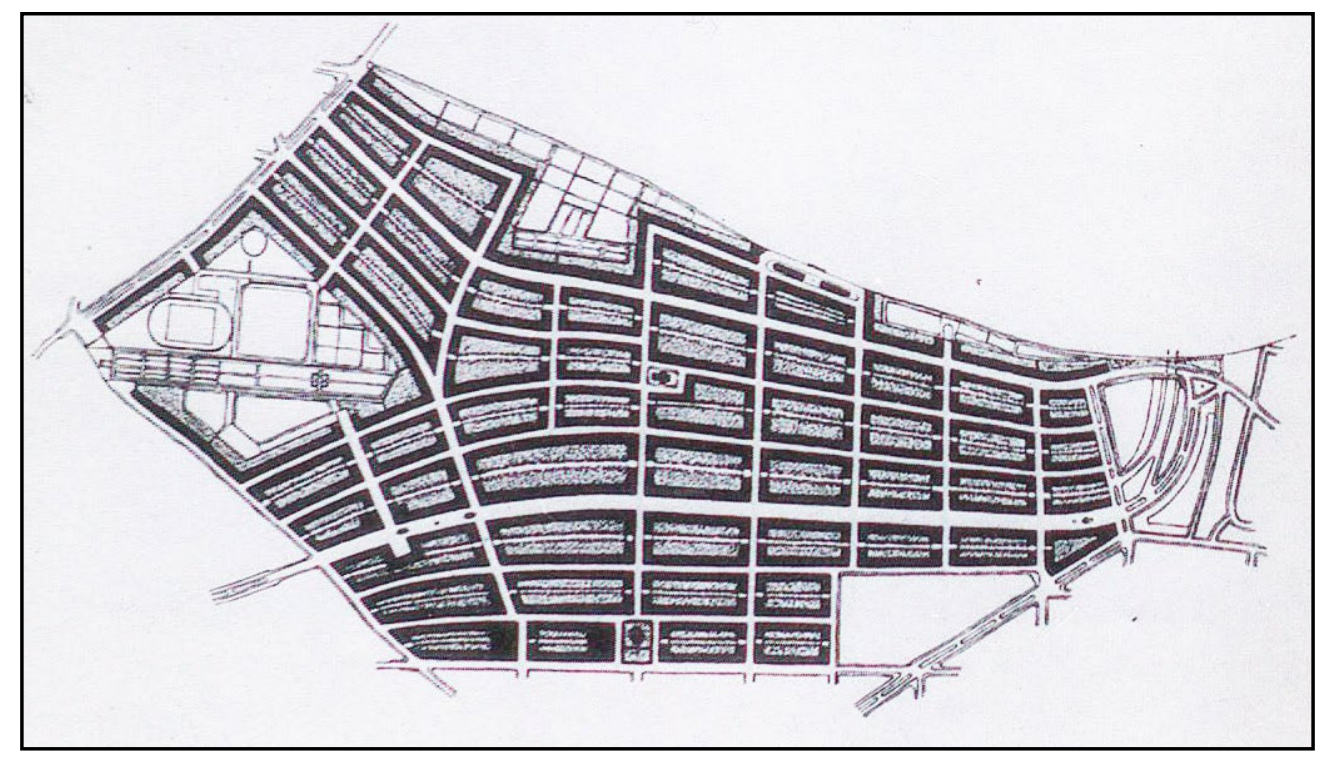

Figura 11. Proyecto del consorcio estadounidense Chapman \& Co. para la Grosssiedlung de Schöneberg.

Fuente: Scarpa, 1983

En ese momento, entre 1924 y 1929, Wagner es también el artífice de la entrada en la escena municipal de un cuarto actor al que los historiadores han prestado menos atención en su retrato de nuestro protagonista: el capital privado, en particular capital financiero nacional y foráneo-especialmente estadounidense-que busca posicionarse en mercados inmobiliarios emergentes, como es el caso de la Alemania del período post-inflación ${ }^{30}$. De hecho buena parte de la promoción de vivienda social de estos años, en Berlín y en otras ciudades, se lleva a cabo gracias a estas fuentes de inversión, en un momento en que el Reichsbank intenta inhibir todo gasto público considerado 'improductivo', esto es, no directamente relacionado con el incremento del potencial industrial de la nación. Haciendo gala de un pragmatismo lúcido, en absoluto ingenuo, Wagner asimila ese principio de austeridad

28 Hartmann, 1976, p. 116.

29 Kracauer, 1930.

30 Balderston, 1983. 
en las cuentas públicas y vislumbra una nueva forma de política urbana municipal que prioriza la captación de capitales de inversión privados. Para ello abogará por un urbanismo dinámico, libre de la rigidez del planeamiento y la normativa convencionales, que deben flexibilizarse para no perder oportunidades de financiación sobrevenidas $^{31}$. Como corolario de esta estrategia el urbanista deviene un gestor de atracciones y plusvalías: las propuestas deben incorporar elementos que permitan atraer la inversión por las expectativas de generación de beneficios; el capital se revela finalmente como el auténtico constructor de ciudad.

Aunque el principio del urbanismo dinámico y la búsqueda de plusvalías que aseguren las operaciones se manifestaron en la política residencial de las Grosssiedlungen-el caso más claro, la irrealizada colonia al sur de Schöneberg (figura 11 ) $^{32}$ su máxima expresión se manifiesta en la estrategia para la remodelación de espacios centrales neurálgicos, allí donde los elevados valores del suelo limitan severamente la acción pública. Ligada a la apuesta del gobierno local por posicionar Berlín en una red emergente de ciudades mundiales (Weltstädte), Wagner propondrá una serie de actuaciones en la escala del proyecto urbano ligadas a espacios de oportunidad, estratégicos por su potencial para transformarse en motores del consumo metropolitano. Así, habla en términos explícitos del urbanismo como una maquinaria que busca atrapar el Konsumkraft (poder de consumo) o Kaufkraft (poder adquisitivo, de compra) de la población en nuevos enclaves de centralidad que combinan atracciones terciarias-fundamentalmente grandes almacenes y espacios de ocio-y una accesibilidad eficiente gracias a la creación de grandes nodos en los que confluyen medios de transporte público y una red viaria ampliada ${ }^{33}$.

Wagner plantea estos principios en una serie de intervenciones a finales de la década de 1920, en solitario o en colaboración con otros colegas ${ }^{34}$. Encontramos una de sus expresiones más acabadas en la charla "Los problemas urbanísticos de la metrópolis" ("Städtebauliche Probleme der Großstadt") 35, dirigida en 1929 a una audiencia entre la que se encuentran empresarios interesados en la inversión en operaciones de remodelación en el centro de Berlín. Wagner indica la necesidad de estudios económicos rigurosos que permitan calibrar el impacto de las intervenciones y, así, asegurar su viabilidad y capacidad para generar beneficios. La ciudad es entendida en esta intervención como un espacio de acumulación de capital fijo, sometido a procesos de obsolescencia y renovación que el urbanista debe comprender para poder manejarlos a su favor en un programa de renovación urbana a medio y largo plazo. Para tal fin Wagner sugiere la identificación de ámbitos estratégicos y la adopción en ellos de un esquema de amortización obligatoria de los bienes construidos y la formación en paralelo de bolsas de suelo de propiedad comunal que faciliten la gestión de operaciones de renovación a gran escala tras la demolición

31 Wagner, 1927; 1929

32 Scarpa, 1983, p. 76-78.

33 M. Wagner, 1985, p. 106.

34 Ver, fundamentalmente, M. Wagner, 1985; Wagner y Hilberseimer, 1929.

35 M. Wagner, 1985. 
del tejido existente ${ }^{36}$. Hay aquí una iluminación sofisticada e inédita: someter al tejido construido a un programa de obsolescencia programada, fijando un plazo de vida útil para los edificios. Por otra parte, la idea de propiedad comunal es esquiva. Como veremos después, no se trata necesariamente de propiedad pública, sino de propiedad colectiva, que puede o no tener un objetivo progresista. En todo caso este esquema conduce a un escenario en el que, manejando períodos de amortización de 25-30 años, cada generación podría construirse una ciudad nueva en respuesta a sus necesidades concretas. Tenemos de nuevo aquí la tensión entre los objetivos sociales de Wagner, el contexto político y económico en el que se ve obligado a operar y las soluciones técnicas y gestoras que idea para responder y mediar entre dichas solicitaciones.

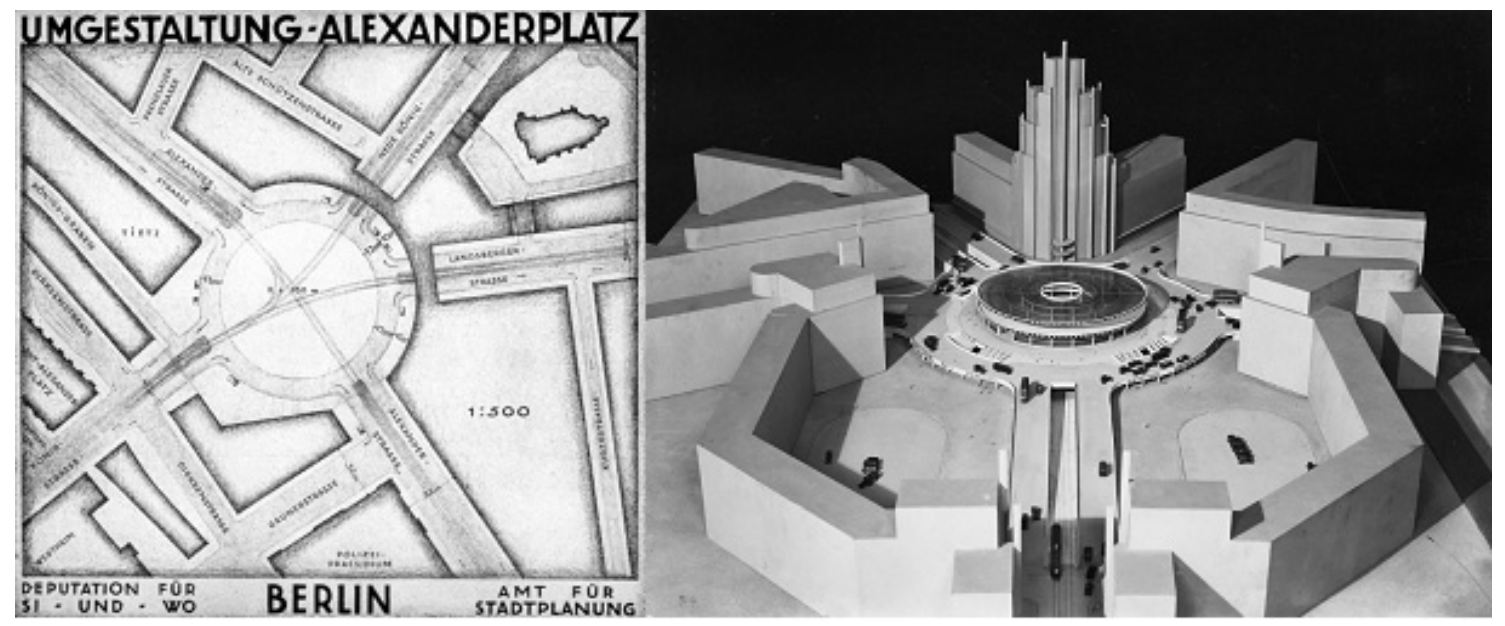

Figura 12. Diseños demostrativos de Martin Wagner para las remodelaciones de Alexanderplatz (izquierda) y el conjunto de Potsdamer Platz y Leipziger Platz (derecha).

Fuente: Das neue Berlin.

Como es habitual en él, esta reflexión está ligada a objetivos de intervención concretos. Durante esos años ha promovido dos grandes concursos de ideas para la remodelación de Alexanderplatz y Potsdamer Platz, iniciativas inscritas en una estrategia más amplia de renovación de un eje estratégico del centro histórico, del que ambas operarían como polos (figura 12) 3 $^{37}$. En línea con los principios que acabamos de comentar, las bases de los concursos plantean la renovación total de estos enclaves, con la demolición de la edificación preexistente y su sustitución por nuevos edificios en altura destinados fundamentalmente a servicios terciarios, junto a una ampliación sustancial de la capacidad de acogida de vehículos y medios de transporte colectivo, que permitiría incrementar la afluencia de potenciales compradores $^{38}$. Más allá de la intervención en las plazas propiamente dichas, estas actuaciones buscaban desencadenar un proceso de cambio más amplio en sus alrededores, incentivando la sustitución a iniciativa privada de espacios de vivienda obrera aún existentes en el centro urbano-especialmente en torno a Alexanderplatz-por el 36 Ibid., p. 104.

37 Scarpa, 1983, p. 103-110.

38 Wagner y Hilberseimer, 1929. 
incremento de los valores del suelo. En este sentido hay que advertir que Wagner, como la mayoría de sus colegas coetáneos, deplora las formas de alojamiento obrero tradicional, no sólo por la insalubridad de las viviendas, también por considerar que ocupan áreas erróneas en el mapa funcional de la ciudad ${ }^{39}$. Así, criticando las medidas que preservan la localización central de los barrios populares, afirmará: “¿Por qué ... mantenemos a millones de ciudadanos en ... lugares que están totalmente muertos? ¿Durante cuánto tiempo vamos a permitir este crimen contra la economía colectiva?"40.

En el caso de Alexanderplatz y Potsdamer Platz se trata de una estrategia consistente, sin plan general que la sustente pero coherente en términos de estructura urbana, proyecto social y económico. El esquema pretende equilibrar la creciente concentración terciaria ya aparente en ese momento al oeste de la ciudad con la renovación del eje entre las dos plazas como una nueva área de servicios de alto nivel. Para tal fin un agregado de propietarios de suelo, empresarios comerciales y financieros ha fundado en 1926 el City-Ausschuss (Comité de la City), órgano dirigido por el urbanista Martin Mächler que opera a modo de lobby con el objetivo explícito de elevar los valores del suelo en Mitte ${ }^{41 .}$ El grupo de arquitectos de vanguardia Der Ring apoya la visión de Mächler de hacer de la reestructuración del centro el motor del desarrollo urbano de la ciudad y de su posicionamiento en el contexto internacional. Wagner ha pertenecido brevemente a dicho grupo y buena parte de los participantes y premiados en los concursos organizados por él son miembros del mismo. Tras sus limpias arquitecturas de torres de vidrio y acero, el urbanismo cosmopolita se convierte en el altar en el que Wagner, atado por el marco de austeridad financiera, sacrifica la centralidad popular en beneficio de la acumulación de capital.

En todo caso, la mayor parte de estas iniciativas quedaron en el papel por las limitaciones económicas y la llegada de la crisis de 1929. Poco después, en 1931, Wagner abandona el SPD, permaneciendo en su cargo de Stadtbaurat hasta su expulsión en 1933 tras la llegada del nacionalsocialismo al poder ${ }^{42}$. Durante este período de inactividad por la atonía general de la economía empieza a dedicarse más activamente a la especulación teórica. Inicia aquí una fase de profundización de intuiciones previas, que se extiende a su etapa americana, caracterizado por la apuesta decidida por un proceso de suburbanización generalizada. El modelo, esbozado en su labor como promotor y coordinador del concurso de vivienda unifamiliar reunido en el volumen Das wachsende Haus (1932), encuentra una primera expresión en el ensayo Die neue Stadt im neuen Land (1934), escrito justo antes de abandonar Alemania ${ }^{43}$. Este trabajo contiene una sorprendente combinación de la tradición de la ciudad-jardín con las intuiciones de postguerra de Bruno Taut sobre la disolución de la ciudad y la formación de nuevos enclaves comunitarios e, incluso, del patrón

39 Wagner, 1934a.

40 Wagner, 1932, p. 56.

41 Deutsche Bauzeitung, 1932.

42 Homann, Kieren y Scarpa, 1985, p. 174.

43 Wagner, 1934b; Wagner, 2015, p. 35-6. 
de asentamiento lineal de Nikolai Miliutin, publicado apenas cuatro años antes ${ }^{44}$. Wagner define su visión de un nuevo modelo de asentamiento regional como una Stadt-Land-Stad $t^{45}$, compuesta de asentamientos lineales en torno a infraestructuras de transporte, formando enclaves de 5.000 habitantes denominados Stadtschaften, con sus correspondientes espacios de sustento (Nahrungsspielräume), articulados a su vez en sistemas urbanos más amplios de 25.000 habitantes ${ }^{46}$. Las ideas en relación al centro de la ciudad comienzan también a adoptar un papel más extremo y estructural. Empleando la noción tautiana de Stadtkrone (corona urbana), Wagner sugiere la reconversión integral de la antigua ciudad en un centro de servicios especializados para toda la región ${ }^{47}$.

\section{Desarrollo: consolidación de un modelo territorial teórico en EE.UU}

Este esquema básico-suburbanización generalizada del tejido residencial y productivo y concentración de usos terciarios conspicuos en un hub regional totalmente reconstruido-será la base sobre la que Wagner desarrolle sus reflexiones posteriores en EE.UU., país al que llega en 1938, tras abandonar la Alemania nazi y después de una estancia intermedia en Turquía. Seguramente nuestro protagonista ha identificado pronto resonancias de su trabajo previo con el debate estadounidense en ese momento de transición entre el primer New Deal y la recuperación económica, pronto alterado por el contexto bélico. El país se encuentra inmerso en un proceso de descentralización de vivienda y actividades industriales. El gobierno federal anima esa dinámica con sus políticas, pero otros actores la observan con alarma: para los gobiernos locales de las grandes ciudades implica una erosión importante de su base fiscal; para los propietarios de suelo en los centros urbanos, un nuevo elemento de devaluación de sus predios por el aumento de espacios vacantes y el creciente predominio de aquellas actividades y grupos más vulnerables, que no pueden permitirse abandonar la ciudad ${ }^{48}$. Así, el debate de la época presta especial atención a la posibilidad de idear un patrón ordenado de asentamiento comunitario en el suburbio y, simultáneamente, de revertir el declive de las áreas centrales, fundamentalmente a través del slum clearance y su sustitución por nuevos complejos de vivienda social. Aunque este esquema opera desde los primeros pasos de la administración Roosevelt, va a cobrar especial protagonismo con vistas a la reactivación de la construcción tras la guerra mundial.

En su labor docente en la primera parte de la década de 1940 Wagner lidia con estos argumentos, adoptándolos o criticándolos, a menudo discutiendo con sus alumnos documentos oficiales y políticas coetáneas. Encontramos evidencias del compromiso de Wagner con estos debates en una contribución temprana, junto a

44 Miliutin, 1974; Taut, 1919.

45 Literalmente 'ciudad-campiña-ciudad'. La traducción al castellano es prácticamente imposible, pues Wagner hace un juego de palabras con el término 'Stadtlandschaft', 'paisaje urbano'.

46 Wagner, 1934b, p. 3-4, 21-3.

47 Ibid., p. 24.

48 Urban Land Institute, 1940; 1942. 
Walter Gropius, en el congreso que la Universidad de Harvard organiza en 1942 bajo el lema "The Problem of the Cities and Towns"49. En el evento participan representantes de diversos organismos oficiales-del Comité para la Planificación de los Recursos Nacionales a la Reserva Federal-, asociaciones de agentes inmobiliarios y expertos académicos. Gropius y Wagner, miembros del comité organizador, preparan el epílogo de las actas, sintetizando las aportaciones del encuentro y proyectándolas más allá, en una intuición formal más detallada que prolonga el modelo ideado por Wagner una década antes y que él mismo está desarrollando en ese momento, solo o con otros colegas, tras su llegada a la Harvard Graduate School of Design. ${ }^{50}$

El formato de esta indagación resulta de especial interés desde el punto de vista académico, pues se trata de una investigación orientada a la docencia y, viceversa, de una exploración especulativa con los alumnos que revierte en posteriores contribuciones teóricas. En lo que sigue atribuyo el impulso principal de este empeño a Wagner, incluso a pesar de que a veces, especialmente en la primera parte de la década de 1940, el trabajo se desarrolla de forma colectiva con otros profesores del centro. Entre las evidencias que sustentan esta hipótesis está el hecho de que nuestro protagonista es el único docente con continuidad en esta línea de indagación durante esa década, desarrollando un modelo que él mismo había prefigurado previamente; no sólo la estructura territorial propuesta, sino los propios conceptos empleados son a veces traducciones directas de las contribuciones alemanas que acabamos de discutir ${ }^{51}$. Aunque se firmen de forma colectiva, la mayor parte de los borradores de los enunciados y memorias de curso se encuentran entre los papeles personales de Wagner; él es además autor único de este tipo de documentos a partir de 1945, cuando el resto de sus colegas, y especialmente Gropius, pierden paulatinamente interés por la dimensión urbanística con el restablecimiento de la actividad constructora y los contratos de edificación tras el final de la guerra. Por último, los ejercicios y documentos producidos durante este período ponen énfasis especial en la economía política del proceso urbanizador, un ingrediente que está ausente de la reflexión de sus colaboradores cuando trabajan en solitario y que Wagner, por el contrario, convertirá en su principal preocupación desde mediados de los 40 y hasta su fallecimiento en 1957.

A través de sus publicaciones en esta época, los ejercicios de sus alumnos y los textos que los acompañan podemos reconstruir un proyecto holístico de 'rehabilitación' territorial ${ }^{52}$. Wagner avanzó explícitamente esta estrategia como un instrumento para asegurar el pleno empleo en el contexto de la desmovilización de 49 Greer, 1942.

50 Gropius y Wagner, 1942a.

51 Por ejemplo los conceptos 'Stadtschaft' I 'township', 'Nachbarschaft' / 'neighborship' o 'Nahrungsraum' / 'space of nourishment'.

52 Aunque en ocasiones los documentos emplean el término 'rehabilitation' como mero sinónimo de 'reconstruction' o 'rebuilding', la formulación más elaborada y consistente emplea estos dos últimos para referirse a la mera sustitución del viejo tejido construido por otro nuevo que conserva la estructura urbana y los usos de suelo preexistentes; 'rehabilitation', por el contrario, designa un esfuerzo de regeneración más amplio, con la relocalización masiva de actividades agrícolas, industriales, servicios y residenciales en un sistema urbano-regional integrado a través de modernas 
postguerra ${ }^{53}$. Aunque su modelo contenía elementos comunes a propuestas previas ${ }^{54}$ sus ideas proporcionaban una mediación poco habitual entre la esfera del diseño y la gestión política y económica que debía sustentar el proceso urbanizador. Con el fin de asegurar la viabilidad de sus propuestas, Wagner se imponía a sí mismo y a sus estudiantes el imperativo intelectual de pensar con el capital, y no contra o sin referencia al mismo 55 . Los urbanistas debían "rechazar toda forma de planificación y diseño ingenuos, no sustentados en hechos sociales y económicos", asumiendo la paradoja de que "sólo la solución ... más ideal y económica será la más práctica y rentable" 56 . Para ello era necesaria "una nueva escuela de pensamiento y acción ... que pruebe con hechos y datos cuán rentables pueden ser las realizaciones ideales de los deseos humanos y cuán utópica era y es la planificación 'realista' si se mide con los instrumentos de la hoja de balance contable y los ingresos generados"

Su visión parte de un análisis de las economías locales, regionales y nacionales, comprendidas como un conjunto de relaciones entre "unidades económicas interdependientes", en tensión perpetua por la atracción de capital y la generación de $v^{v a l o r}{ }^{58}$. Prolongando las reflexiones de su etapa alemana, Wagner lee el capital como una sustancia que fluye a través del entorno construido, distribuyéndose de acuerdo a la capacidad y eficacia del tejido infraestructural de cada unidad para atraparlo en forma de inversión o consumo ${ }^{59}$. La destrucción de empleo durante la Gran Depresión se asocia a procesos de obsolescencia de capital fijo, descentralización de población y actividad económica, y depreciación inmobiliaria, que son a su vez entendidos como síntomas de la fase terminal del ciclo del capital, la "enfermedad" de "metrópolis moribundas"60. De forma más general, Wagner habla de los slums residenciales e industriales, las ciudades-fantasma y las regiones deprimidas como epifenómenos de un modelo único de desarrollo geográfico desigual a distintas escalas $^{61}$. En la segunda mitad de la década de 1940 esta reflexión sobre las raíces de la corrosión de lo urbano y la necesidad de una rehabilitación total se extenderá más allá del contexto americano, aplicándose tanto a ciudades lentamente erosionadas por la fuga de capitales como a ciudades destruidas instantáneamente por los bombardeos de la guerra ${ }^{62}$.

La rehabilitación de la ciudad central se inscribía en un modelo de urbanización

infraestructuras de comunicación. Wagner, 1949b, p. 15.

53 Wagner, 1945, p. 52-3.

54 Quizá el ejemplo más obvio era la propuesta de Rexford Guy Tugwell, director de la Resettlement Administration y una referencia habitual para Wagner. El esquema inicial de Tugwell para el programa de Greenbelt Towns de la RA consistía también en un doble movimiento de reasentamiento suburbano y des-densificación en la ciudad central, liberando suelo para creación de parques. Ese modelo, sin embargo, no llegó a concretarse en lo que se refería a la ciudad central.

55 Ver por ej. Wagner, 1949a; 1950a; 1950b; y, sobre todo, 1951, p. 55-66.

56 Gropius et al., 1941, p. 5.

57 Wagner, 1945, p. 258.

58 Wagner, 1945, p. 61-2; 1957, p. 284.

59 Wagner, 1949a, p. 37-8; Gropius y Wagner, 1942b, p. 8-9.

60 Wagner y Gropius, 1943, p. 12; Wagner, 1956.

61 Gropius y Wagner, 1942b, p. 12-3; Wagner y Gropius, 1942, p. 64.

62 Wagner, 1948a, p. 130. 
regional-metropolitana más amplio, que en cierto modo sintetiza y supera las preocupaciones que, de forma sectorial, ocupaban a los colegas y agencias coetáneos (figura 13).

La propuesta parte de una reorganización general previa de los hinterlands como espacios mixtos industrial-agrícolas que absorben las poblaciones metropolitanas excedentes y quedan estrechamente imbricados entre sí y con el centro regional ${ }^{63}$, en consonancia con un contexto que ve consumarse la disolución de la divisoria campo-ciudad. La unidad básica de la reordenación de la región son los 'townships', “células urbanas a escala humana ... dispersas ... a lo largo de las mejores vías de transporte", "un nuevo tipo de ... asentamiento que forma parte de una nueva ciudad-campiña (country-town) en una nueva 'campiña-ciudad' ('town-country')"64. La creación de esta cadena de asentamientos liberaría a la metrópoli de su mayor carga: las actividades económicas obsoletas y la población desempleada asociada a ellas ${ }^{65}$.

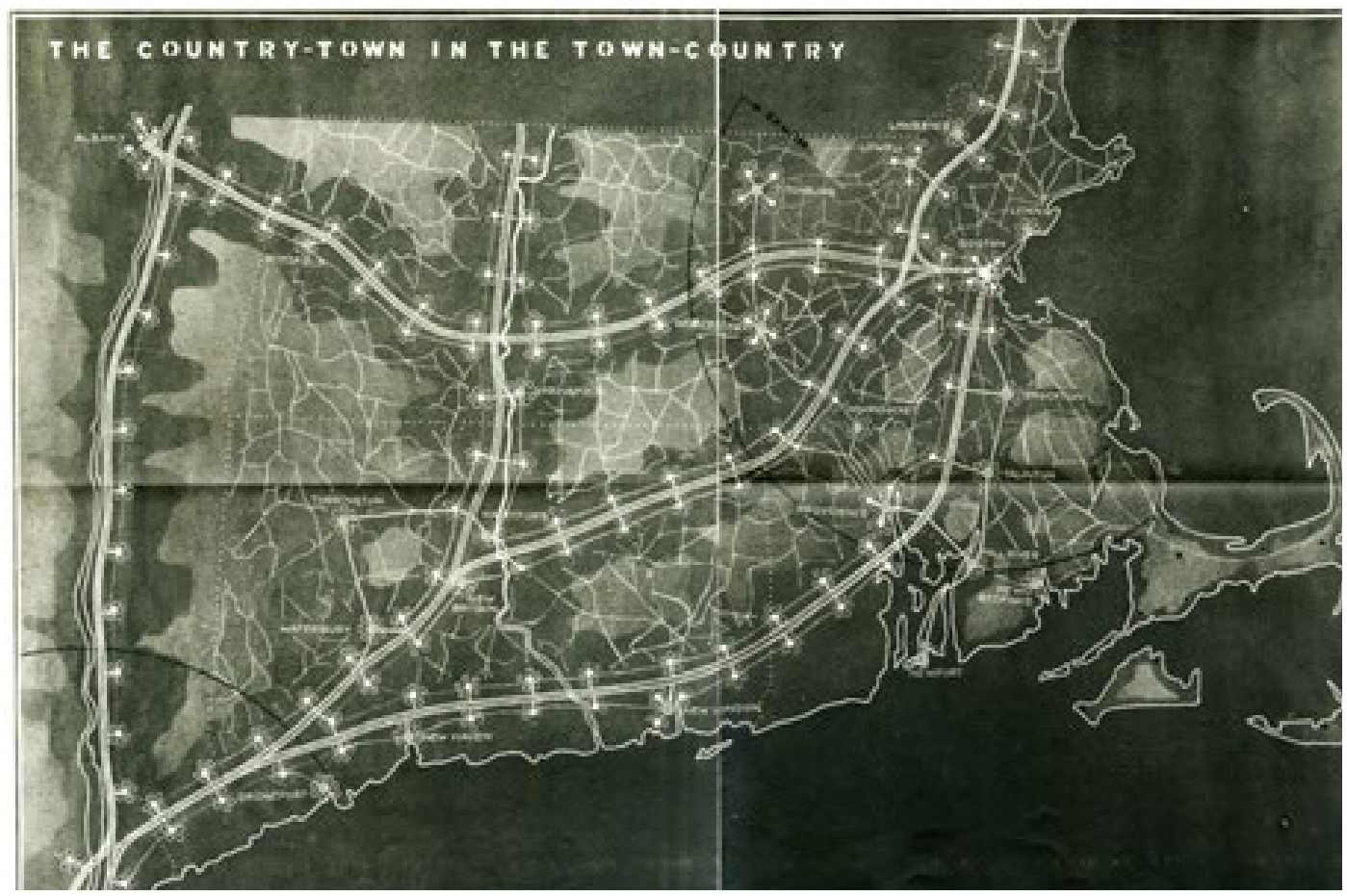

Figura 13. Wagner, esquema para un nuevo patrón de asentamiento regional entre Boston y Nueva York, hacia 1939.

Fuente: Frances Loeb Library, Harvard University Graduate School of Design.

Ambas desencadenan un círculo vicioso que debe ser neutralizado: producen 63 Wagner, 1946a, p. 67; 1951, p. 82.

64 Gropius y Wagner, 1942b, p. 21; Wagner y Gropius, 1943, p. 30-1. El término empleado por Wagner en 1934 es similar, ver Wagner, 1934b, p. 18-24. Gropius y Wagner hablarán también de 'country-cities in city-countries' y de 'ciudades-jardín insertas en jardines-ciudad regionales' ("garden-cities embedded in regional city-gardens') en Gropius et al., 1941, p. 11; Gropius y Wagner, 1942a, p. 102; 1943, p. 75. Wagner elaborará una fórmula aún más compleja al hablar de “un grupo orgánico de ciudades-jardín (Gartenstädten) en paisajes-ciudad (Stadt-Landschaften), es decir, en unidades donde las forma-ciudad (Stadtschaft), la forma-bosque (Waldschaft) y la forma-campo (Feldschaft) se mezclan y penetran entre sí' (Wagner, 1951, p. 19).

65 Gropius y Wagner, 1942a, p. 101. 
un aumento de los gastos públicos de asistencia, que a su vez incrementa la presión fiscal, incentivando aún más los procesos de descentralización de población y actividades, y la consiguiente obsolescencia y devaluación ${ }^{66}$. Junto al realojamiento de la población debe producirse la relocalización gradual de aquellas actividades económicas de los centros urbanos que "han sido ya afectadas por la ley de rendimientos decrecientes", antes de que sean "suprimidas por una obsolescencia prematura" ${ }^{67}$. Simultáneamente debe procederse a la adquisición paulatina de los suelos liberados en el viejo centro urbano, un proceso lento y complejo, para el que Wagner formulará distintas alternativas. La rehabilitación física de estos centros regionales sería, en consecuencia, el último episodio del "largo proceso de reconstrucción de la ciudad"68. Los ejercicios para la creación de nuevos townships van a desarrollarse en tres cursos en las primaveras de 1941, 1942 y 1946, con la colaboración de profesores de los tres departamentos de Graduate School of Design, en ese momento designados como arquitectura, planificación regional y arquitectura del paisaje ${ }^{69}$. El trabajo de los alumnos está estrechamente guiado por los enunciados de los ejercicios, que identifican sucesivas áreas del entorno metropolitano de Boston, bien conectadas por infraestructuras existentes o previstas en los planes federales o estatales (figuras $13,14)^{70}$.

Los alumnos deben seleccionar la ubicación final de los asentamientos de acuerdo a una evaluación cuantitativa de diversos factores, desde el precio del suelo a aspectos paisajísticos, ambientales y legales ${ }^{71}$. Los nuevos enclaves tendrían una población de 5.000 habitantes; cuando se alcanzara esta cifra, se crearía un nuevo asentamiento $^{72}$. Su estructura debía seguir el principio de la unidad vecinal, asegurando acceso peatonal a los espacios de trabajo, comercio, equipamientos y centro comunitario $^{73}$. Las soluciones de los alumnos muestran tejidos de muy baja densidad, entre 10 y 20 viv./Ha., ocupados fundamentalmente por vivienda unifamiliar ${ }^{74}$.

La mayor parte de la población trabajaría en plantas industriales locales-incluidas también en los diseños-en jornadas de 30 horas que permitirían disponer de tres turnos diarios, asegurando el pleno empleo y maximizando la productividad de las colonias ${ }^{75}$.

66 Gropius y Wagner, 1942b, p. 16.

67 El uso recurrente de conceptos de economía política como este, manejado por los economistas clásicos y después por Marx, es otro indicio de la autoría de Wagner sobre los textos publicados con Gropius, que rara vez maneja este tipo de jerga en sus escritos individuales.

68 Gropius y Wagner, 1943, p. 85.

69 Alofsin, 2002, p. 127-129, 172-174.

70 Ver por ejemplo Gropius et al., 1941, p. 8-9.

71 Wagner, 1946a, p. 65-6, 68-71; Wagner, 1948b, p. 194.

72 Wagner, 1946a, p. 73-4.

73 Wagner y Gropius, 1943, p. 17. Las distintas propuestas a lo largo de diversos cursos presentarían pequeñas variaciones en el tamaño de población y densidad. Ver por ejemplo Gropius y Wagner, 1943, p. 79. Las soluciones muestran numerosos paralelismos con la noción de 'unidad vecinal' de Clarence Perry, pero también diferencias sustanciales, especialmente en relación a la inclusión de actividades económicas. Ver Perry, 1929.

74 Gropius y Wagner, 1943, p. 80; Wagner, 1948b, p. 192; 1951, p. 24.

75 Gropius et al.,1941, p. 10; Gropius y Wagner, 1943, p. 30; Wagner, 1945, p. 50-1, 175. 


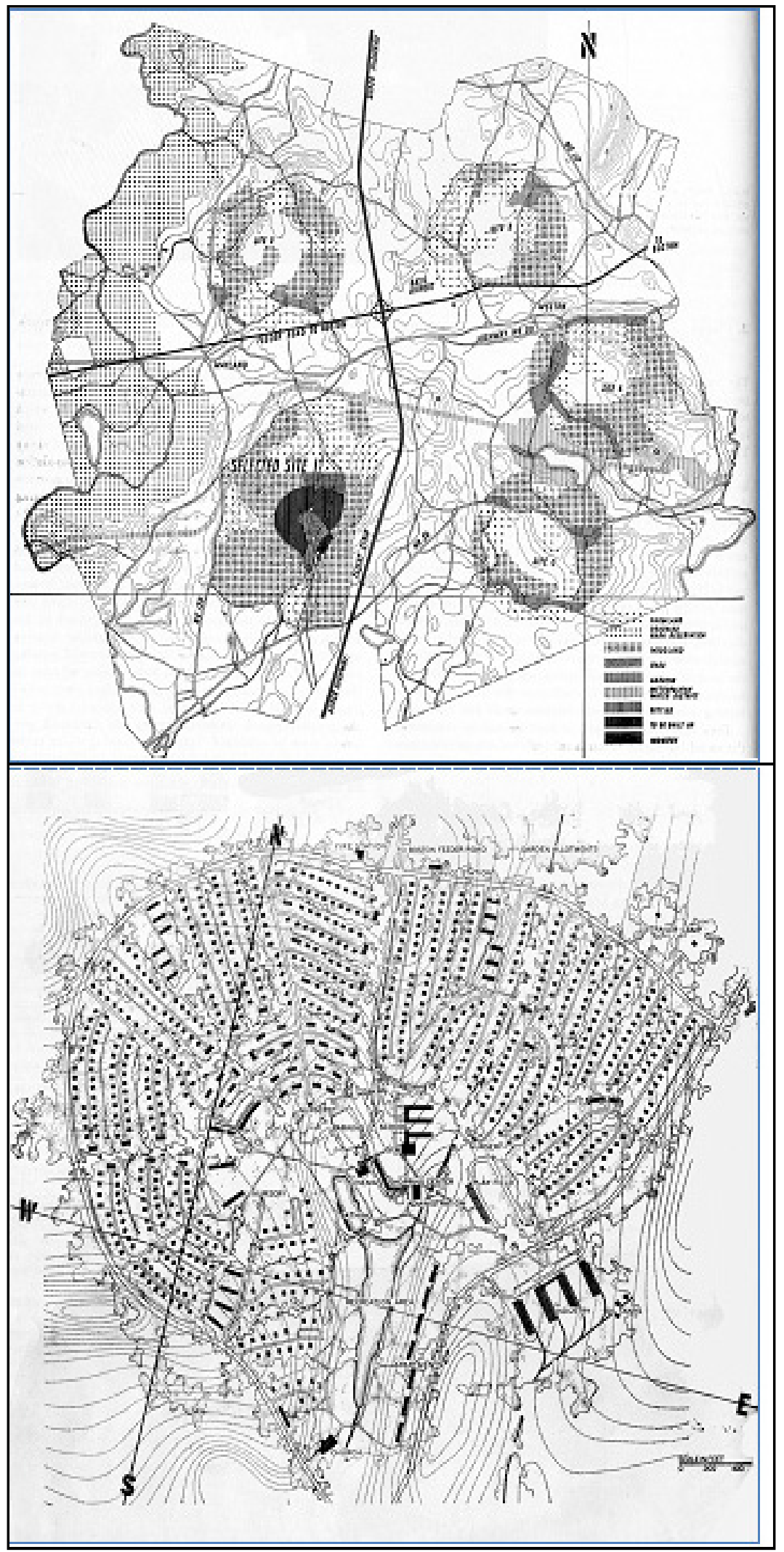

Figuras 14 y 15. Propuesta de 'township' a partir de los ejercicios de alumnos de 1941 y 1942 . Plano de situación de un conjunto de asentamientos y diseño general de uno de ellos. Fuente: Gropius y Wagner, 1943. 
La configuración formal de estas unidades prescinde de geometrías simples, empleando estructuras de organización que buscan la disolución del tejido construido en el paisaje circundante (figuras 15, 16, 17). La edificación pierde protagonismo y la forma urbana confía más activamente en la concepción del landscape architect: "En nuestro nuevo township el paisaje se convertirá en un elemento integral y orgánico de la región y penetrará las distintas partes del enclave, nutriendo así la forja de una nueva cultura"76. Las vías de penetración del tráfico rodado en fondo de saco se alternan con ejes verdes que conectan el centro del asentamiento con los espacios agrícolas y forestales circundantes, pautando las 'comunidades-manzana' ('block-communities'), unidad de agrupación residencial con su propio servicio de guardería ${ }^{77}$.

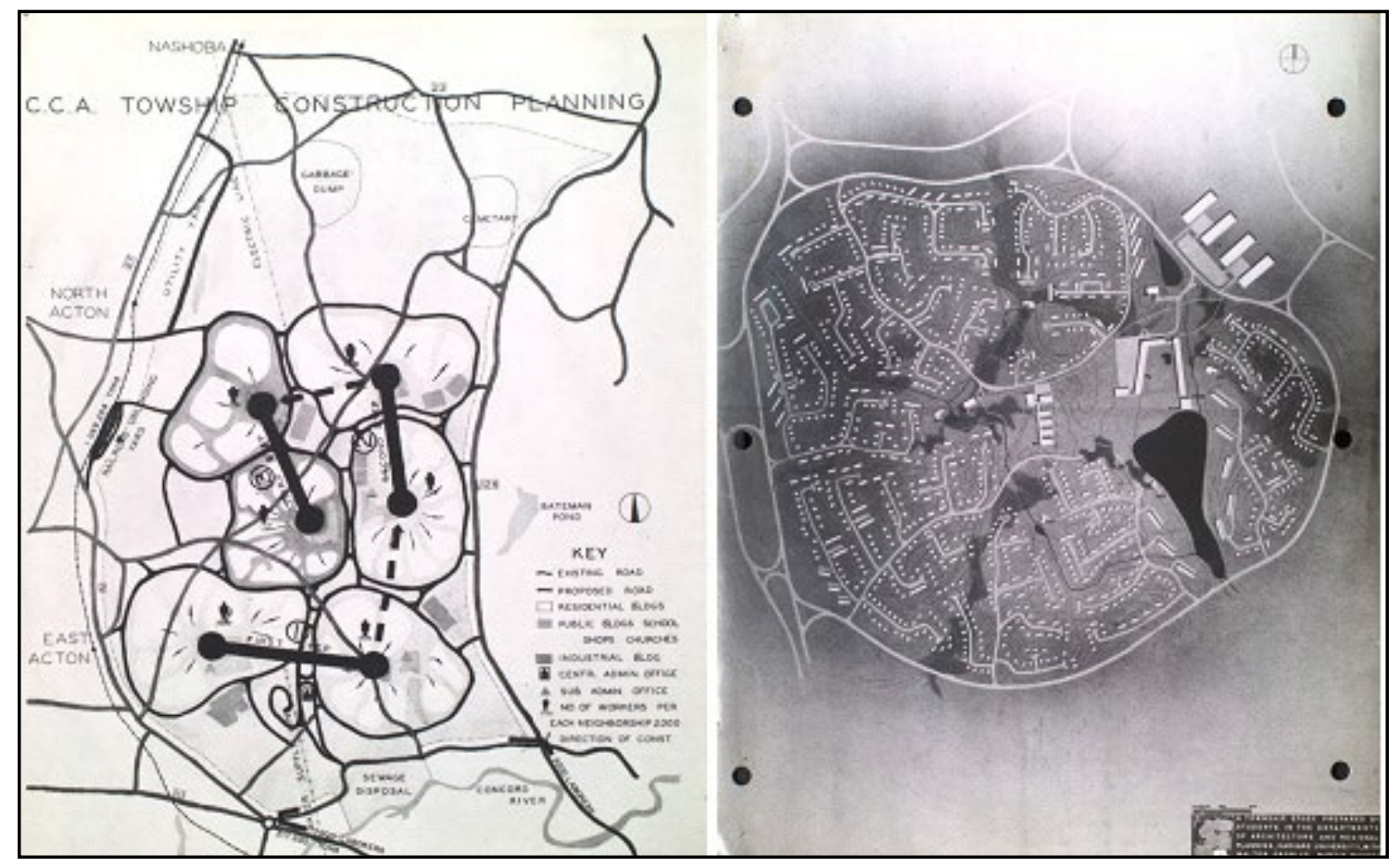

Figuras 16 y 17. Propuesta de 'townships' de 1946. Esquema general de interacción de las distintas unidades y detalle de un 'township'

Fuente: Frances Loeb Library, Harvard University Graduate School of Design

La red doble de espacio verde-peatonal y calles rodadas se despliega como un haz en torno al centro comunitario, en el que se ubica un área comercial y un hotel, instalaciones de ocio y deportivas, escuela e instituto, servicios administrativos y zona de aparcamiento ${ }^{78}$. Más allá de la ascendencia obvia de los modelos de ciu-

76 Los alumnos del departamento de arquitectura del paisaje participaron también en algunos de los ejercicios coordinados por Wagner y Gropius, pero siguiendo un enunciado específico (Gropius y Wagner, 1942b, p. 42). Gropius y Wagner, 1942b, p. 45; ver también Gropius et, al., 1941, p. 13; Wagner, 1948b, p. 195.

77 Wagner, 1946a, p. 84.

78 Gropius y Wagner, 1943, p. 80, 82. 
dad-jardín y unidad vecinal, las sucesivas versiones de este esquema en los distintos cursos dejan entrever una influencia más directa de dos experiencias por las que Wagner mostrará interés en sus escritos: las Greenbelt Towns de la Resettlement Administration, especialmente Greenbelt, Maryland y Greenhills, Ohio; y el pequeño poblado de Norris, Tennessee, parte del programa de planificación regional de la Tennessee Valley Authority ${ }^{79}$.

Interesa también destacar que los ejercicios plantean la necesidad de considerar no sólo la localización y ordenación de los nuevos townships, sino también sus 'espacios de sustento' ('spaces of nourishment'so), hinterlands agrarios y forestales que ocupan alrededor de la mitad del suelo de las propuestas y en los que se ubican granjas y explotaciones con vínculos estrechos con la comunidad suburbana ${ }^{81}$. Este es, quizá, el elemento de mayor cercanía al modelo original que Howard propusiera para su ciudad-jardín. Las granjas proporcionan oportunidades adicionales de empleo para los residentes en el township-de forma permanente o, más habitualmente, temporal, asociado a picos de producción estacionales-y se benefician de mayores ingresos gracias a la eliminación de intermediarios en la distribución de sus productos, que se realiza directamente a los mercados locales y regionales. Además, las aguas residuales de los asentamientos son tratadas y reaprovechadas en las granjas como fertilizantes ${ }^{82}$. En conjunto, estas medidas permitirían reactivar la actividad agropecuaria en entornos metropolitanos, un sector ya en aquel momento en profunda regresión.

La dimensión suburbana del modelo presenta, en todo caso, el aspecto luminoso de la estrategia de Wagner. Es al volver a la ciudad central cuando encontramos la faceta más negativa y contradictoria no sólo con el pasado político de nuestro protagonista, sino también con su propia retórica en la etapa americana, cargada de proclamas sobre el compromiso del urbanista con la comunidad ${ }^{83}$. Habiendo identificado la suburbanización masiva de la población trabajadora como un principio de interés general, se trata ahora de readaptar los espacios centrales de las ciudades desocupadas como enclaves de servicios de escala regional y nacional ${ }^{84}$. Unidos, ambos movimientos suponen una limpieza social y funcional de los núcleos urbanos, en la que los estratos populares son desposeídos de la centralidad urbana que ellos mismos han producido y trasladados a enclaves con una configuración que impide su reproducción. Además, la declinación de lo comunal que Wagner idea para gestionar la remodelación de la ciudad consolidada resulta sumamente problemática.

79 La influencia iba más allá de lo puramente morfológico. Wagner citará con frecuencia a Arthur E. Morgan, antiguo cargo de la TVA durante la creación de Norris, como referencia imprescindible sobre la reflexión coetánea en torno a las nuevas comunidades.

80 Se trata de una traducción literal del alemán 'Nahrungsraum' que Wagner emplea en sus escritos, a su vez derivado de 'Nahrungsspielraum', noción manejada por diversos geógrafos alemanes de finales del XIX y principios del XX y por Max Weber.

81 Gropius y Wagner, 1943, p. 79; Wagner, 1946a, p. 72.

82 Wagner, 1946b, p. 335.

83 Gropius y Wagner, 1942a. Gropius participa sólo en uno de los seminarios centrados en la renovación del centro urbano; ver Wagner y Gropius, 1942.

84 Wagner y Gropius, 1942; Wagner, 1944; Wagner, 1948a. 
En su programa los propietarios de suelo deben consolidar sus predios en una bolsa común, o pool, configurándose como capital social en una empresa de dividendos limitados; primarían los principios empresariales de viabilidad de la operación de rehabilitación y maximización de beneficios. En este esquema la administración pública participa del proceso como un propietario más, aportando sus suelos al pool de suelo ${ }^{85}$.

Como hemos visto, durante su etapa alemana Wagner había recomendado a sindicatos y administraciones públicas actuar con la mentalidad y procedimientos de una corporación privada para sobrevivir en un contexto capitalista y asegurar así la consecución de sus objetivos de welfare. Esta estrategia encuentra en los EE.UU. una expresión más desarrollada, en la que los propietarios mismos prescinden de la administración en la iniciativa urbanística, si bien la mayor parte de las propuestas plantean que ésta debe quedar circunscrita al marco fijado por un órgano de planificación estatal o paraestatal. Sin duda el contexto liberal estadounidense ha ejercido una influencia notable en esta formulación descarnada del horizonte de la urbanización capitalista. Hay que tener en cuenta sin embargo que estas propuestas son elaboradas cuando el sector políticamente más progresista de planificadores y policy-makers del país está abogando por un incremento del control e iniciativa estatales en el proceso urbanizador, con la consolidación del credo keynesiano que será dominante en la postguerra. Wagner compartirá parcialmente esta perspectiva en la primera mitad de la década de 1940, pero sus propuestas posteriores abandonan dicho enfoque para abrazar una versión mucho más cruda de la economía política de la urbanización capitalista.

Wagner organizó en GSD varios cursos tomando el centro de Boston como ámbito de intervención y publicó ampliamente sobre el tema de la rehabilitación de ciudades, tomando a menudo el trabajo de los alumnos como ilustración de sus ideas. Incluso presentaría los primeros resultados de esta indagación colectiva como propuesta en el Boston Contest, concurso que en 1944 invita a la contribución de esquemas de planificación general para la ciudad y su área metropolitana ${ }^{86}$. A pesar de que el director de su centro, Joseph Hudnut, figura entre los miembros del jurado, la entrada de Wagner quedará sin reconocimiento alguno por su propuesta radical de demoler integralmente el área central de la ciudad. En todo caso es importante tener en cuenta que nuestro protagonista presentó normalmente sus soluciones como "diagramas" preliminares, esquemas de ideas que debían ser adecuadamente desarrollados con posterioridad, no como proyectos acabados ${ }^{87}$.

Para Wagner la sustitución integral de los centros urbanos no es el exceso caprichoso de un diseñador iluminado, sino una regularidad histórica $y$, sobre todo, una necesidad económica. Según él, en el momento en que escribe la única diferencia respecto al pasado es que los ciclos económicos y la lógica del capital aceleran ese proceso, demandando renovaciones cíclicas cada 25-30 años. Como hemos visto, la

85 Wagner, 1948a, p. 136; 1951, p. 62-4, 85-6, 96-7, 167-8.

86 Diefendorf, 2015, p. xv-xvi; Wagner, 1944.

87 Wagner y Gropius, 1942, apéndice 12. 
idea de una ciudad de vida breve, funcional a las necesidades de una sola generación, había sido ya formulada en su etapa alemana, asociada a la reflexión sobre la renovación de espacios públicos centrales. Durante la etapa americana resurge también, de forma más virulenta, la crítica a los "pestilentes slums que amenazan con pudrir en el propio corazón de las ciudades lo que aún queda de vital y merecedor de conservación o regeneración" ${ }^{88}$. Ligado a ella articula un ataque a las políticas coetáneas de vivienda social, identificándolas como el principal factor de pérdidas económicas para las ciudades ${ }^{89}$. Aunque la opción del slum-clearance era la tónica en ese momento, la visión de Wagner se desmarca totalmente de sus contemporáneos, pues sugiere "el uso de suelos ocupados por slums para ubicar actividades económicas altamente rentables y para realojar a parte de las clases con mayores ingresos ... Los suelos del centro urbano tienen una necesidad urgente de ser sustentados por el poder adquisitivo de las clases más adineradas" ${ }^{\prime \prime 0}$. Como comentábamos al principio de este artículo, la propuesta, totalmente inédita en su momento, presagiaba los procesos de urban renewal de las décadas venideras, en particular en relación al West End de Boston y el área en torno a Scollay Square ${ }^{91}$.

Además de las propias viviendas de trabajadores, Wagner proponía eliminar las actividades productivas y comerciales que fueran incoherentes con la condición conspicua del centro regional ${ }^{92}$, es decir, precisamente aquéllas que sustentaban la vida cotidiana de los barrios populares en las esferas del trabajo, el consumo o el ocio: talleres, pequeños comercios y servicios, lugares de encuentro de la comunidad, etc. En los centros urbanos estas actividades constituían "focos patológicos" que deberían ser privados de cualquier tipo de estímulo, hasta su extinción ${ }^{93}$. En un inesperado giro que roza el sadismo político, Wagner señala que, en los barrios obreros, deben "recortarse los servicios públicos que no sean rentables (¡como haría cualquier empresa privada!)"94 con el fin de desincentivar su continuidad. En su lugar deben disponerse complejos de centros comerciales y establecimientos especializados, bancos y edificios de oficinas, acompañados de sedes de gobierno y administración, complejos culturales, hoteles y espacios residenciales para la élite ${ }^{95}$. En un razonamiento que anticipa ulteriores rondas de urbanismo neoliberal, Wagner sugiere que para atraer la inversión de capitales es necesario fijar en estos enclaves el potencial de consumo no sólo de la élite urbana y las masas suburbanas, sino también de las burguesías internacionales, por lo que los urbanistas deben reservar para ellos las principales atracciones comerciales, culturales y políticas ${ }^{96}$. Sólo los servicios terciarios de primer orden pueden hacer viable la costosa iniciativa de re88 Wagner, 1945, p. 68, 208-9.

89 Wagner, 1957, p. 283.

90 Wagner, 1945, p. 217-9, 221.

91 Para una historia de la renovación urbana en estos enclaves ver Gilbert, 2007; Fisher y Hughes, 1992; O'Connor, 1993, p. 124-142.

92 Wagner, 1948a, p. 130, 136.

93 Wagner, 1951, p. 93.

94 Wagner, 1949a, p. 39-40.

95 Wagner, 1945, p. 181-2; Wagner y Gropius, 1943, p. 31; 1942, p. 34-6.

96 Wagner, 1950c, p. 143; 1956, p. 272. 
habilitación integral por su capacidad para "pagar las rentas más altas"97_la "corona de la ciudad" de Taut deviene así un puro espacio de consumo cosmopolita, espectáculo y dirección corporativa.

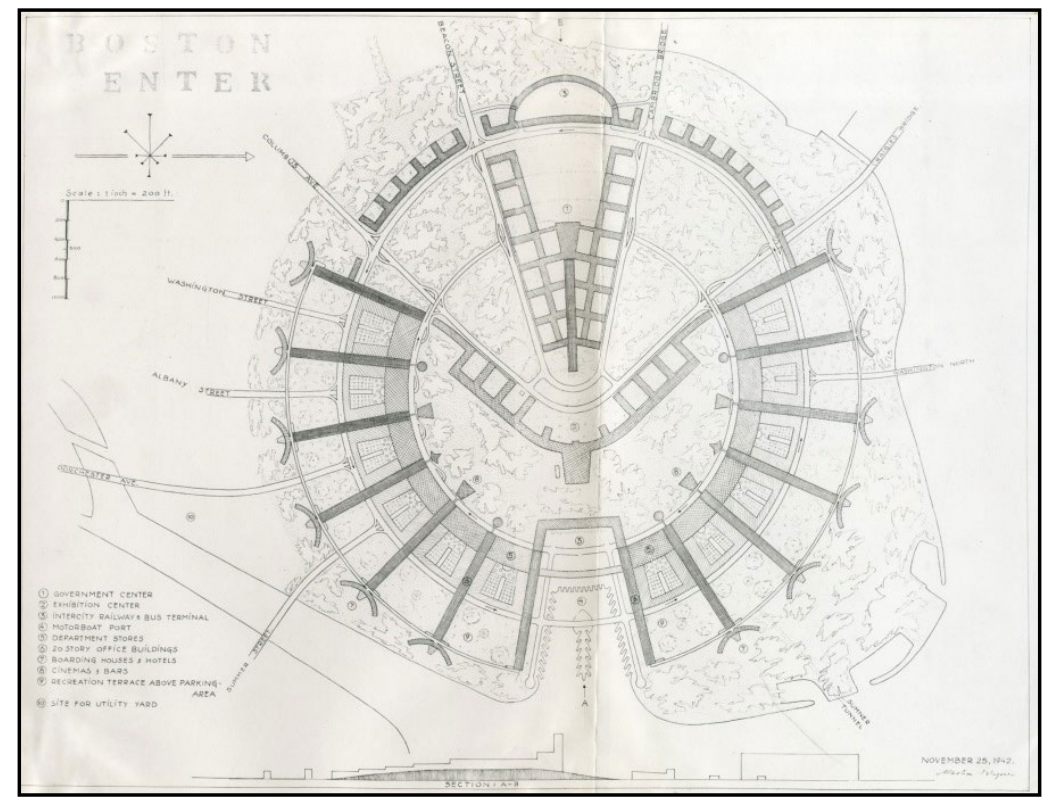

Figura 18. Propuesta de 1942 para la 'rehabilitación integral' del centro de Boston. El conjunto de la península es demolido para crear grandes almacenes, espacios culturales y administrativos. Fuente: Frances Loeb Library, Harvard University Graduate School of Design

Wagner sintetiza estos cambios drásticos en la distribución de usos del suelo en su teoría de la "rotación del cultivo" ("crop rotation"), que de nuevo atiende al imperativo de trabajar con el capital, de emplear la planificación para activar y encauzar su circulación por el entorno construido: “La rehabilitación urbana no puede ejecutarse para preservar los mismos usos en el mismo lugar. Las distintas clases de cada ciudad migran de barrio a barrio de acuerdo con su mayor o menor poder adquisitivo, los cambios familiares, la obsolescencia de los edificios, etc. Así, los planificadores tendrán que cambiar el 'cultivo' si desean rehabilitar un área determinada de la ciudad de forma rentable" ${ }^{\prime \prime 9}$.

Las ideas de Wagner nutren el trabajo de los alumnos en el primer ejercicio sobre este tema, desarrollado en 1942 (figura 18), dónde se anima a éstos a liberar el centro de Boston toda actividad "indeseable" para atraer el poder adquisitivo suburbano". Aunque Gropius participó en el proyecto el resultado lleva la impronta de Wagner, que firma los dibujos de síntesis en la memoria de curso post-festum, base para su propia entrada en el Boston Contest de $1944^{100}$. En ellos una rígida macro-estructura en forma de arco de circunferencia, ocupada íntegramente por grandes almacenes,

97 Wagner y Gropius, 1942, p. 35.

98 Wagner, 1949b, p. 14.

99 Wagner y Gropius, 1942, p. 14-18.

100 Wagner y Gropius, 1942, apéndice. 
se extiende por una arrasada península de Boston, rodeando un amplio parque en cuyo centro se ubica un centro de exposiciones, alineado simétricamente en un eje compartido con el rascacielos del centro de gobierno. El edificio comercial queda pautado por una serie de bloques de oficinas de 20 plantas, en cuyos extremos se ubican hoteles, clubs y otros espacios recreativos. Casi la mitad de la península queda ocupada bajo rasante por aparcamientos que multiplicarían por doce la capacidad existente en ese momento en la ciudad ${ }^{101}$, albergando las hordas de consumidores suburbanos que afluirían regularmente al centro.

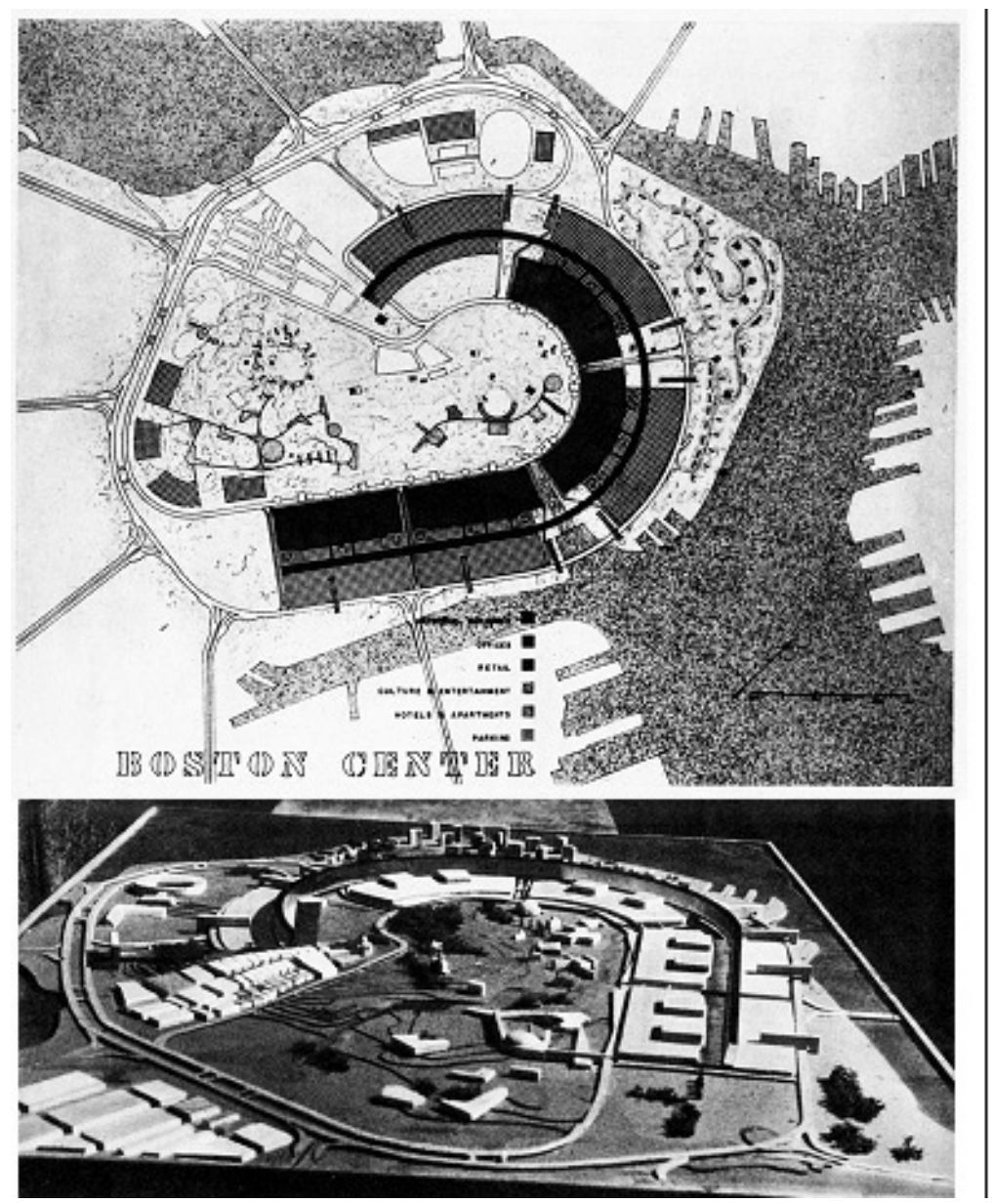

Figura 19. Propuesta de 1948 para el centro de Boston. Fuente: Wagner, 1948a.

Unos años después Wagner volverá a proponer a sus alumnos un ejercicio similar, que publicará más tarde como ejemplo para la reconstrucción de ciudades en la Alemania de postguerra. Se parte de un enfoque algo más moderado, en el que se conservan edificios históricos singulares y el barrio de Beacon Hill (figura 19) ${ }^{102}$.

La propuesta, más elaborada en términos formales pero igualmente mastodóntica, reduciría drásticamente la edificabilidad de la ciudad, distribuyéndola en cinco 101 Wagner y Gropius, 1942, p. 16-8.

102 Wagner, 1948a. 
"unidades económicas" articuladas a estaciones de metro y compuestas, de nuevo, por centros comerciales, una vasta zona de aparcamiento, áreas recreativas y un rascacielos de oficinas ${ }^{103}$. Estas cinco unidades, ubicadas en las áreas con valores del suelo más bajos en torno a la desembocadura en la bahía y por tanto más fáciles de "liberar" para su demolición, debían servir para relocalizar todas las actividades merecedoras de seguir en la península, procediendo tras ello a la demolición del resto del tejido no protegido, creando un parque continuo, edificios culturales y recreativos, y hoteles y residencia de lujo ${ }^{104}$.

\section{Ruinas: el déficit político de la arquitectura moderna}

Ha sido Manfredo Tafuri el principal responsable de elevar a nuestro protagonista a la condición de epítome casi heroico de las contradicciones del Movimiento Moderno. El Berlín de Wagner fue para el italiano uno de los "capítulos más importantes en la historia de la planificación urbana moderna"105 y él mismo se convierte en ejemplo de una nueva generación de técnicos que abandonan las tradicionales consolaciones estéticas de los arquitectos para mediar en los procesos de producción urbana, con todos sus conflictos ${ }^{106}$. Ese proyecto-que Tafuri tiende a identificar con el conjunto de la vanguardia arquitectónica de entreguerras-tendría por objetivo la "integración del diseño, a todos sus niveles [en] la reorganización de la producción, la distribución y el consumo en la ciudad capitalista"107. Algunos de los actores de este proceso han albergado expectativas genuinas y realmente progresistas por dotar a ese proceso de una orientación reformista, pero el 'Plan' del capital que pretendían guiar ha terminado subsumiéndolos, convirtiendo el diseño en objeto de una maquinaria más amplia que asimila el proceso de racionalización al que apuntan estas experiencias y lo pone al servicio de nuevas rondas de acumulación ${ }^{108}$.

Tafuri no conocía el trabajo de Wagner en EE.UU. o, al menos, no se ocupó de él, aunque sin duda éste podría inscribirse dentro de la misma contradicción. Con todo, hay un aspecto de la ideología arquitectónica común a Wagner y otros colegas sobre el que Tafuri pasa de puntillas: la distancia insalvable con las comunidades obreras y populares realmente existentes. En el cierre del texto que estamos comentando el historiador señala sucintamente que la arquitectura moderna sella su destino al hacerse portadora de ideales de progreso y racionalización que son ajenos a la clase trabajadora ${ }^{109}$. Me gustaría terminar este artículo reflexionando brevemente sobre este aspecto, pues en él reside en mi opinión la principal causa del déficit politico que sugerí al principio: la incapacidad del bloque dominante y fundacional de la arquitectura moderna para superar los campos ciegos fijados por su propia condi-

103 Wagner, 1948a, p. 136.

104 Wagner, 1948a, p. 129.

105 Tafuri, 1998, p. 23.

106 Tafuri, 1984.

107 Tafuri, 1998, p. 15.

108 Tafuri, 1998, p. 28-9.

109 Tafuri, 1998, p. 32. 
ción corporativa y de clase, a pesar de la militancia activa de algunos de sus padres ideológicos ${ }^{110}$. Combinadas y articuladas a otras determinaciones locales y políticas, estas dos perspectivas han creado una desconexión fundamental entre la inmensa mayoría de arquitectos de la vanguardia histórica comprometidos con un proyecto progresista y el pueblo para el cual, supuestamente, trabajaban.

Volvamos a Wagner para ilustrar esta constelación de la ideología arquitectónica. Para describir el rol del arquitecto-urbanista en la rehabilitación de la ciudad nuestro protagonista recurrió a menudo, tanto en Alemania como en EE.UU., a una metáfora que resultará familiar a los lectores que hayan pasado por una escuela de arquitectura: el arquitecto como "director de orquesta" encargado de liderar "concepciones creativas", coordinando especialistas de alto nivel en materia de finanzas, legislación, construcción y actividad empresarial, y también artistas, ciudadanos cosmopolitas y comunidades culturales ${ }^{111}$. Desgraciadamente esta voluntad de hegemonía corporativa ha conducido a Wagner-persona por lo demás inquieta y profundamente cultivada, a la vista de las referencias en sus textos-a denostar el trabajo de las ciencias sociales que empezaban en esa época a implicarse en análisis urbanos a pie de campo y a descubrir la complejidad de la vida cotidiana en contacto directo con comunidades populares ${ }^{112}$. Para nuestro protagonista la sensibilidad del arquitecto-urbanista integra en su análisis intuitivo la problemática social, haciendo superfluos ese tipo de estudios, un argumento aún hoy habitual en nuestras aulas.

Esta postura ha influido sin duda en el desconocimiento de la realidad cotidiana de los barrios de trabajadores que Wagner muestra en sus escritos, a su vez causa del impacto que sus propuestas habrían producido en dichos ámbitos. En su planteamiento, como en el de otros miembros de las vanguardias dentro y fuera de la esfera del diseño y el arte, el pueblo se convierte en una mera representación, un constructo intelectual ligado a una concepción heterónoma del orden social. En el olímpico desprecio que Wagner manifiesta hacia estas comunidades se revela también el sesgo de clase que confunde la mirada de la pequeña burguesía intelectual. Así, dedicará frases muy duras a estos espacios, que califica como una "fea caricatura de la vida comunal"113. La matriz ideológica a través de la que observa la ciudad le impide comprender el rol que las redes informales de apoyo mutuo habituales en este tipo de enclaves étnicos y de clase desempeñan en el sustento de las clases populares y, especialmente, de aquellos que ve como principal problema en estos

110 Mumford, 2009.

111 El sesgo de clase en los actores es obvio. Ver Wagner, 1951, p. 176-7; 1985; s.f. (2), p. 25.

112 Resulta revelador en este sentido el intercambio con su amiga Catherine Bauer, arquitecta más joven, profesora en Harvard y defensora de nuevas políticas residenciales durante el New Deal. Durante la década de 1940 Bauer comenzó a colaborar con un grupo de jóvenes sociólogos y psicólogos ambientales de MIT interesados en comprender las dinámicas de vida cotidiana en barrios populares. En un intercambio informal Bauer aconseja a Wagner estos trabajos porque según ella se encuentran cercanos a su posicionamiento político y en las antípodas de Le Corbusier. Wagner, sin embargo, se mofará de un campo que considera pseudo-ciencia, llamando a los colegas de Bauer 'microbios'. Wagner, 1949a, p. 22-4.

113 Wagner, 1945, p. b. 
espacios: los desempleados y sus familias ${ }^{114}$. En términos lefebvrianos, Wagner no ha apreciado que su programa suprime la condición de centralidad que disfrutaban las poblaciones de barrios populares en ese momento, es decir: tanto la complejidad funcional que permite resolver las necesidades de vida cotidiana en un entorno de proximidad, como la presencia de redes de socialización y organización que aseguran niveles relativos de autonomía, autogestión y soberanía espacial. Las nuevas comunidades - tanto las que coordina en Berlín como las imaginadas para Boston-no sólo son incapaces de reproducir esa condición desde arriba; también inhiben su aparición espontánea con sus programas funcionales y configuraciones espaciales cerrados.

En cierto sentido, la ideología arquitectónica que vemos aquí en marcha bloquea el compromiso de servicio social que muchos arquitectos modernos, sin duda bienintencionados, se han fijado como meta de su labor. Quizá sea esa la tragedia implícita a la arquitectura moderna: su propia visión elitista y distante le impidió ofrecer soluciones emancipadoras a los problemas sociales que legítima y sinceramente aspiró a resolver. El dilema recuerda, en cierto modo, al planteado por Jacques Rancière en El maestro ignorante ${ }^{115}$, donde se sugiere que toda actividad política/pedagógica-y no hay dudas sobre la voluntad de la arquitectura de este período de re-educar a la población-debe asumir la igualdad entre actor y receptor como punto de partida, y no como objetivo a alcanzar a través de una forma más o menos revolucionaria de praxis social que eleve el segundo al nivel del primero. De lo contrario dichos actores pueden reproducir las desigualdades que supuestamente pretenden eliminar. Su praxis, en consecuencia, debe afirmar a cada paso esa igualdad constitutiva, trabajando para desmontar los órdenes jerárquicos y los principios de autoridad que la ponen en peligro. Las contradicciones de la vanguardia histórica no son, en todo caso, exclusivas al período de entreguerras y la inmediata postguerra. Pueden, desde luego, rastrearse también en experiencias posteriores, hasta la actualidad. Empleando el término de Ivan Illich ${ }^{116}$, pero yendo más allá de la interpretación que éste da a su concepto, podemos hablar de la arquitectura y el diseño urbano en estas coordenadas como un conocimiento doblemente 'inhabilitante': una técnica que no sólo impide formas subalternas de producción del espacio por su creciente monopolio de la construcción de ciudad, sino que, de forma más profunda, también dificulta a los propios profesionales un acceso directo y veraz a los objetos con los que han de lidiar, produciendo un desplazamiento fatal en el conocimiento, las significaciones y sentidos que aquéllos construyen a partir de éstos.

Wagner compartió ese credo con buena parte de sus compañeros de generación, incluso con aquellos a los que criticó duramente por su distanciamiento de la realidad de la gestión urbanística. Como ellos, sin embargo, apeló retóricamente a una

114 Para comprender cómo funcionaban estas dinámicas en los barrios populares de Boston sigue siendo imprescindible volver al clásico de Herbert Gans, The Urban Villagers, cuyo trabajo de campo se realiza inmediatamente antes de la demolición del West End; Gans, 1962.

115 Rancière, 1987.

116 Illich, 1977. 
colectividad que demanda una ciudad nueva, interpretando la voluntad del pueblo sin ocuparse de establecer canales de comunicación o participación para éste. Incluso, en uno de sus momentos más extremos, sugirió que "es una mala comprensión de la democracia dejar a la 'gente de la calle' elegir al alcalde o cualquier otro cargo experto"117, proponiendo a continuación una limitación de la capacidad de elección directa de representantes por encima del nivel barrial. Esta perspectiva ha sido común a toda una generación de intelectuales de entreguerras, también más allá de la esfera del diseño. Pensemos, por ejemplo, en el cuadro que dibujara Ortega y Gasset en La rebelión de las masas al hablar del peligro de la 'hiperdemocracia' y la necesidad de encomendar el proyecto social a un selecto grupo de 'minorías excelentes' que habrían de guiar al hombre-masa. Sería interesante, para el campo del diseño, reflexionar sobre los motivos por los que este tipo de afirmaciones son hoy casi imposibles de encontrar en los discursos de otras disciplinas pero siguen resultando habituales en las escuelas de arquitectura.

Esa debilidad política, en todo caso, ha permitido en su momento a Wagner prefigurar algunas de las transformaciones más profundas en los modelos espaciales, financieros y de gestión que el capitalismo va a imponer al proceso urbanizador en décadas posteriores: la explosión del suburbio como nuevo paisaje cotidiano para las clases medias; las campañas de urban renewal para la penetración de grandes infraestructuras de transporte en los centros urbanos y la creación de enclaves para clases acomodadas; el retroceso de las agencias públicas en los modelos de gestión y el creciente predominio de conglomerados privados y partenariados público-privados en el desarrollo de operaciones de remodelación urbana de gran escala; la 'mallificación' de los centros metropolitanos y su subsunción en estrategias de marketing urbano que buscan posicionarlos en un panorama de competencia global; la destrucción de la centralidad popular y los procesos de aculturación asociados a la implantación heterónoma de un modelo normalizado de cosmopolitismo; o la deriva del urbanista en su devenir un mero gestor de atracciones y espectáculos, captador de capitales de inversión que asume acríticamente las dinámicas de desarrollo geográfico desigual e intenta aprovecharlas como nuevos instrumentos de diseño. Hay, sin duda, una lección positiva implícita en esta parábola. Incluso en sus horas más oscuras-o precisamente en ellas-la imaginación arquitectónica puede ser índice del alcance de una urbanización capitalista por venir. En el caso de Wagner esta dolorosa "virtud" ha recaído sobre una de las figuras que la disciplina ha identificado como portadora del proyecto de emancipación social de la modernidad-una ironía que abre el horizonte a una reconsideración crítica de los discursos y relatos que nos hemos otorgado.

117 Wagner, 1946b, p. 325. 


\section{Bibliografía}

AA.VV. Cuatro Siedlungen berlinesas de la República de Weimar. Madrid: Colegio Oficial de Arquitectos de Madrid, 1992.

ALOFSIN, Anthony. The Struggle for Modernism: Architecture, Landscape Architecture, and City Planning at Harvard. New York: W.W. Norton \& Company, 2002.

BALDERSTON, T. The Beginning of the Depression in Germany, 1927-30: Investment and the Capital Market. The Economic History Review, New Series, vol. 36, $\mathrm{n}^{\circ}$ 3, 1983, p. 395-415.

BOSTON REDEVELOPMENT AUTHORITY. A History of Boston's Government Center: Research Report. Boston: BRA, 1970.

DEUTSCHE BAUZEITUNG. Programm des Berliner City-Auschusses. Deutsche Bauzeitung vol. 16, 1932.

DIEFENDORF, Jeffry M. The Boston Contest: Introduction. In The Boston Contest of 1944: Prize Winning Programs. New York: Routledge, 2015, p. vii-xx.

FISHER, Sean M. y HUGHES, Carolyn (eds.) The Last Tenement: Confronting Community and Urban Renewal in Boston's West End. Boston: Bostonian Society, 1992.

FRIED, Marc y GLEICHER, Peggy. Some. Some sources of residential satisfaction in an urban slum. Journal of the American Institute of Planners, 1961, vol.27(4), p.305315.

GANS, Herbert J. The Urban Villagers: Group and Class in the Life of Italian-Americans. New York: Free Press of Glencoe, 1962.

GILBERT, Daniel A. 'Why Dwell on a Lurid Memory?': Deviance and Redevelopment in Boston's Scollay Square. Massachusetts Historical Review, 2007, vol. 9, p. 103-133.

GRAVAGNUOLO, Benedetto. Historia del urbanismo en Europa, 1750-1960. Madrid: Akal, 1998.

GREER, Guy (ed.) The Problem of the Cities and Towns. Report of the Conference on Urbanism, Harvard University, March 5-6, 1942. Cambridge, Ma., 1942.

GROPIUS, Walter, NEWTON, Norman, STUBBINS, Hugh, TUNNARD, Christopher, and WAGNER, Martin. Housing Problem: Problem 5 for the $2 \mathrm{c}$ Classes and the $2 \mathrm{~d}$ Class. Texto mecanografiado en la Frances Loeb Library - Special Collections Rare, Harvard University, 1941.

GROPIUS, Walter, y WAGNER, Martin. Epilogue: The New City Pattern for the People and by the People. In GREER, Guy (ed.) The Problem of the Cities and Towns. Report of the Conference on Urbanism, Harvard University, March 5-6, 1942. Cambridge, Ma., 1942a, p. 95-116.

GROPIUS, Walter, y WAGNER, Martin. Housing as a Townbuilding Problem. A Post-War Problem for the Students of the Graduate School of Design, Harvard University, February-March. Texto mecanografiado en la Frances Loeb Library - Special Collections Rare, Harvard University, 1942b.

GROPIUS, Walter, y WAGNER, Martin. A Program for City Reconstruction. The Architectural Forum, 1943, vol. 79(1), p. 75-86. 
HARTMANN, Kristiana, Deutsche Gartenstadtbewegung: Kulturpolitik und Gesellschaftsreform. München: H. Moos, 1976.

HOMANN, Klaus, KIEREN, Martin, y SCARPA, Ludovica. Martin Wagner 18851957. Wohnungsbau und Weltstadtplanung. Die Rationalisierung des Glücks. Berlin: Akademie der Künste, 1985.

ILLICH, Ivan. Disabling professions. In ILLICH, Ivan et al. Disabling Professions. London: Marion Boyars, 1977, p. 11-40.

KAUFMANN, Georg. Die Dewog-Organisation in Deutschland. Gewerkschaftliche Rundschau, 1932, vol. 1, p. 12-18.

KOLINSKI, Eva, y VAN DER WILL, Wilfried. The Cambridge Companion to Modern German Culture. Cambridge: Cambridge University Press, 1998.

KRACAUER, Siegfried. Die Angestellten; Aus Dem Neuesten Deutschland. Frankfurt Am Main: Frankfurter Societäts-Druckerei, 1930.

KRUH, David. Always Something Doing: Boston's Infamous Scollay Square. Ed. Rev. Boston: Northeastern University Press, 1999.

LINNEKE, Richard. Die Dewog-Organisation in Deutschland. Das Wohnen, 1931, vol. 6(1), p. 1-3.

MEYER, Hannes. El arquitecto en la lucha de clases y otros escritos (1921-42) Gustavo Gili, Barcelona, 1972.

MILIUTIN, Nikolai A. Sotsgorod. The problem of building socialist cities. Cambridge, Ma.: MIT Press, 1974. Primera ed. 1930.

MOLLENKOPF, John H. The Contested City. Princeton, N.J.: Princeton University Press, 1983.

MUMFORD, Eric. CIAM and the Communist Bloc, 1928-59, The Journal of Architecture, 2009, vol. 14, p. 237-254.

MURRAY, Robert K. Red Scare: A Study in National Hysteria, 1919-1920. Westport, Conn.: Greenwood Press, 1980.

O'CONNOR, Thomas H. Building a New Boston: Politics and Urban Renewal, 19501970. Boston: Northeastern University Press, 1993.

PERRY, Clarence. The Neighborhood Unit. In ADAMS, Thomas (ed.) Neighborhood and Community Planning, Regional Survey, vol. VII. Regional Plan of New York and its Environs. New York, 1929, p. 22-140.

RANCIÈRE, Jacques. Le maître ignorant: cinq leçons sur l'émancipation intellectuelle. Paris: Fayard, 1987.

SAMBRICIO, Carlos. Cuatro colonias berlinesas en la República de Weimar. In Berlin: Estado actual del Planeamiento Urbano. Madrid: Ministerio de Cultura, 1991, p. 13-46.

SCARPA, Ludovica. Martin Wagner e Berlino. Casa e città nella Repubblica di Weimar, 1918-1933. Roma: Officina, 1983.

TAFURI, Manfredo. Sozialpolitik y ciudad en la Alemania de Weimar. In TAFURI, Manfredo, La esfera y el laberinto, Barcelona: Gustavo Gili, 1984 [1971 ], p. 237-392.

TAFURI, Manfredo. Toward a critique of architectural ideology. In HAYS, K. Mi- 
chael (ed.) Architecture, theory, since 1968. Cambridge, Ma: MIT Press, 1998 [1969], p. 6-35.

TAUT, Bruno. Die Stadtkrone. Jena: E. Diedrichs, 1919.

TEAFORD, Jon C. The Rough Road to Renaissance: Urban Revitalization in America, 1940-1985. Baltimore: Johns Hopkins University Press, 1990.

URBAN LAND INSTITUTE. Decentralization. What is it Doing to our Cities? Chicago, 1940.

URBAN LAND INSTITUTE. A Proposal for Rebuilding Blighted City Areas. Washington, 1942.

VERBAND SOZIALER BAUBETRIEBE. Bauhüttenarbeit. Berlin: Verband Sozialer Baubetriebe, 1928.

WAGNER, Bernhard. Martin Wagner, 1885-1957. Leben und Werk. Hamburg: Wittenborn Söhne, 1985.

WAGNER, Martin. Zur kommende Umbildung Berlins. Notwendigkeit einer plamässiger Führung, Bauwelt 1927, vol. 18, p. 707-709.

WAGNER, Martin. Der Platz der Republik. Das neue Berlin, 1929, vol. 1, p. 69-72.

WAGNER, Martin. Sterbende Städte? Oder Planwirtschaftlicher Städtebau? Die neue Stadt, 1932, no 3, p. 50-59.

WAGNER, Martin. Die Sanierung der Berliner 'City'. Deutsche Bauzeitung, 1934a, $\mathrm{n}^{0} 68, \mathrm{p} .142-146$.

WAGNER, Martin. Die neue Stadt im neuen Land. Berlin: Karl Buchholz, 1934b.

WAGNER, Martin. The Boston Contest. Texto mecanografiado en la Frances Loeb Library - Special Collections Rare, Harvard University, 1944.

WAGNER, Martin. City Rehabilitation. Texto mecanografiado en la Frances Loeb Library - Special Collections Rare, Harvard University, 1945.

WAGNER, Martin. Townlets and Towns: A Study on City Reconstruction Made by the Students of the Graduate School of Design, Harvard University. Texto mecanografiado en la Frances Loeb Library - Special Collections Rare, Harvard University, 1946a.

WAGNER, Martin. American versus German City Planning. The Journal of Land \& Public Utility Economics, 1946b, vol. 22(4), p. 321-338.

WAGNER, Martin. Der Neubau der City. Baurundschau, 1948a, vol. 38(17/18), p. 130-160.

WAGNER, Martin. Die Stadtschaft auf dem Reissbrett - Eine Studentenvision. Bauen und Wohnen, 1948b, vol. 3(8), p. 188-199.

WAGNER, Martin. New Town Economy. Fall-Problem. Martin Wagner Papers, folder 13/48, Texto mecanografiado en la Frances Loeb Library - Special Collections Rare, Harvard University, 1949a.

WAGNER, Martin. The Balance Sheet. A Plannning Tool. Texto mecanografiado en la Frances Loeb Library - Special Collections Rare, Harvard University, $1949 b$.

WAGNER, Martin. Städtebau Im Kostenspiegel. Neue Stadt, 1950a, vol. 4(6), p. 240-242. 
WAGNER, Martin. Die Vermögensbilanz der Stadt - Ein Instrument der Planung! Mitteilungen des Deutschen Verbandes für Wohnungswesen, Städtebau und Raumplanung, 1950b, no 3-4, p. 35-42.

WAGNER, Martin. Vernunft-Perspektiven im Städtebau. Neue Stadt, 1950c, no 4 , p. 140-143.

WAGNER, Martin. Wirtschaftlicher Städtebau. Stuttgart: J. Hoffmann, 1951.

WAGNER, Martin. Bauen für die Massen. Die Neue Gesellschaft, 1956, vol. 3(4), p. 264-272.

WAGNER, Martin. Unwirtschaftliche der Millionenstädte. In VOGLER, Paul y KÜHN, Erich (ed.) Medizin und Städtebau. Ein Handbuch für Gesundheitlichen Städtebau. München: Urban \& Schwarzenberg, 1957, p. 283-293.

WAGNER, Martin. Städtebauliche Probleme der Großstadt. In HOMANN, Klaus, KIEREN, Martin y SCARPA, Ludovica (eds.) Martin Wagner 1885-1957. Wohnungsbau und Weltstadtplanung. Die Rationalisierung des Glücks. Berlin: Akademie der Künste, 1985, p. 102-107.

WAGNER, Martin. Das wachsende Haus: ein Beitrag zur Lösung der städtischen Wohnungsfrage. Leipzig: Spector Books, 2015. Primera ed. 1932.

WAGNER, Martin. Housing A 6. Site planning 1. Martin Wagner Papers, carpeta 15, documento 16, Special Collections, Frances Loeb Library, Harvard University, texto mecanografiado, s.f. ( 1 )

WAGNER, Martin. Building the builders. Martin Wagner Papers, carpeta 30, documento 1, Special Collections, Frances Loeb Library, Harvard University, texto mecanografiado, s.f. (2)

WAGNER, Martin, y GROPIUS, Walter. The New Boston Center: A Planning Problem for Harvard University's School of Design. Texto mecanografiado en la Frances Loeb Library - Special Collections Rare, Harvard University, 1942.

WAGNER, Martin, y GROPIUS, Walter. Cities' Renaissance. The Kenyon Review, 1943, vol. 5(1), p. 12-33.

WAGNER, Martin, y HILBERSEIMER, Ludwig. Das Formenproblem eines Weltstadtplatzes. Das neue Berlin, 1929, vol. 1, p. 33-41.

(C) Copyright: Álvaro Sevilla-Buitrago, 2017

(c) Copyright Scripta Nova, 2017.

Ficha bibliográfica:

SEVILLA-BUITRAGO, Álvaro.Aporías de una ideología urbanística: arquitectura, territorio y capitalismo en el trabajo de Martin Wagner. Scripta Nova. Revista Electrónica de Geografía y Ciencias Sociales. [En línea]. Barcelona: Universidad de Barcelona, 1 de mayo de 2017, vol. XXI, $n^{0}$ 565. [ISSN: 1138-9788]. 